\title{
Guidance of Axons by Local Coupling of Retrograde Flow to Point Contact Adhesions
}

\author{
Robert H. Nichol IV, ${ }^{1}$ Kate M. Hagen, ${ }^{2}$ Derek C. Lumbard, ${ }^{2}$ Erik W. Dent, ${ }^{1,2}$ and Timothy M. Gómez ${ }^{1,2}$ \\ ${ }^{1}$ Neuroscience Training Program and ${ }^{2}$ Department of Neuroscience, University of Wisconsin, Madison, Wisconsin 53706
}

Growth cones interact with the extracellular matrix (ECM) through integrin receptors at adhesion sites termed point contacts. Point contact adhesions link ECM proteins to the actin cytoskeleton through numerous adaptor and signaling proteins. One presumed function of growth cone point contacts is to restrain or "clutch" myosin-II-based filamentous actin (F-actin) retrograde flow (RF) to promote leading edge membrane protrusion. In motile non-neuronal cells, myosin-II binds and exerts force upon actin filaments at the leading edge, where clutching forces occur. However, in growth cones, it is unclear whether similar F-actin-clutching forces affect axon outgrowth and guidance. Here, we show in Xenopus spinal neurons that RF is reduced in rapidly migrating growth cones on laminin (LN) compared with non-integrin-binding poly-D-lysine (PDL). Moreover, acute stimulation with LN accelerates axon outgrowth over a time course that correlates with point contact formation and reduced RF. These results suggest that RF is restricted by the assembly of point contacts, which we show occurs locally by two-channel imaging of RF and paxillin. Further, using micropatterns of PDL and LN, we demonstrate that individual growth cones have differential RF rates while interacting with two distinct substrata. Opposing effects on RF rates were also observed in growth cones treated with chemoattractive and chemorepulsive axon guidance cues that influence point contact adhesions. Finally, we show that RF is significantly attenuated in vivo, suggesting that it is restrained by molecular clutching forces within the spinal cord. Together, our results suggest that local clutching of RF can control axon guidance on ECM proteins downstream of axon guidance cues.

Key words: actin retrograde flow; axon guidance; growth cone; kabiramide C; molecular clutch; point contact adhesion

\section{Significance Statement}

Here, we correlate point contact adhesions directly with clutching of filamentous actin retrograde flow (RF), which our findings strongly suggest guides developing axons. Acute assembly of new point contact adhesions is temporally and spatially linked to attenuation of RF at sites of forward membrane protrusion. Importantly, clutching of RF is modulated by extracellular matrix (ECM) proteins and soluble axon guidance cues, suggesting that it may regulate axon guidance in vivo. Consistent with this notion, we found that RF rates of spinal neuron growth cones were slower in vivo than what was observed in vitro. Together, our study provides the best evidence that growth cone-ECM adhesions clutch RF locally to guide axons in vivo.

\section{Introduction}

The proper function of the adult nervous system depends on accurate guidance of axons to their correct synaptic targets during early development. Inaccurate neural network wiring may be an underlying cause of a number of severe neurodevelopmental

\footnotetext{
Received July 9, 2015; revised Nov. 20, 2015; accepted Jan. 3, 2016.

Author contributions: R.H.N., E.W.D., and T.M.G. designed research; R.H.N., K.M.H., D.C.L., and T.M.G. performed research; R.H.N., K.M.H., D.C.L., and T.M.G. analyzed data; R.H.N., E.W.D., and T.M.G. wrote the paper.

This work was supported by the National Institutes of Health (Grants R56NS41564 and R21NS88477 to T.M.G., Grant R01NS080928 to E.W.D., and Grant T32GM007507 to the Neuroscience Training Program). We thank members of the Gómez laboratory for comments on the manuscript.

The authors declare no competing financial interests.

Correspondence should be addressed to Timothy M. Gómez, Department of Neuroscience and Neuroscience Training Program, 5433 Wisconsin Institute for Medical Research II, 1111 Highland Ave., Madison, WI 53706. E-mail: tmgomez@wisc.edu.

DOI:10.1523/JNEUROSCI.2645-15.2016

Copyright $\odot 2016$ the authors $\quad 0270-6474 / 16 / 362267-16 \$ 15.00 / 0$
}

disorders, including tuberous sclerosis complex, fragile $\mathrm{X}$ syndrome, and other autism spectrum disorders (Weitzdoerfer et al., 2001; Antar et al., 2006; Nie et al., 2010). Axon guidance involves stabilizing leading edge membrane protrusions of axonal growth cones to the extracellular matrix (ECM). Membrane protrusions are stabilized at growth cone adhesion sites, termed point contacts (Woo and Gómez, 2006; Myers et al., 2011). Point contacts form after integrin receptors bind ECM ligands, leading to receptor clustering and recruitment of adhesion proteins such as talin, paxillin, and vinculin (Woo and Gómez, 2006; Myers and Gómez, 2011; Myers et al., 2011), which link integrins to the actin cytoskeleton. The formation and turnover of point contacts at the growth cone periphery is regulated by the cell substratum and soluble growth factors and strongly correlates with growth cone advance (Woo and Gómez, 2006; Myers et al., 2011). In nonneuronal cells, the formation and stabilization of adhesions 

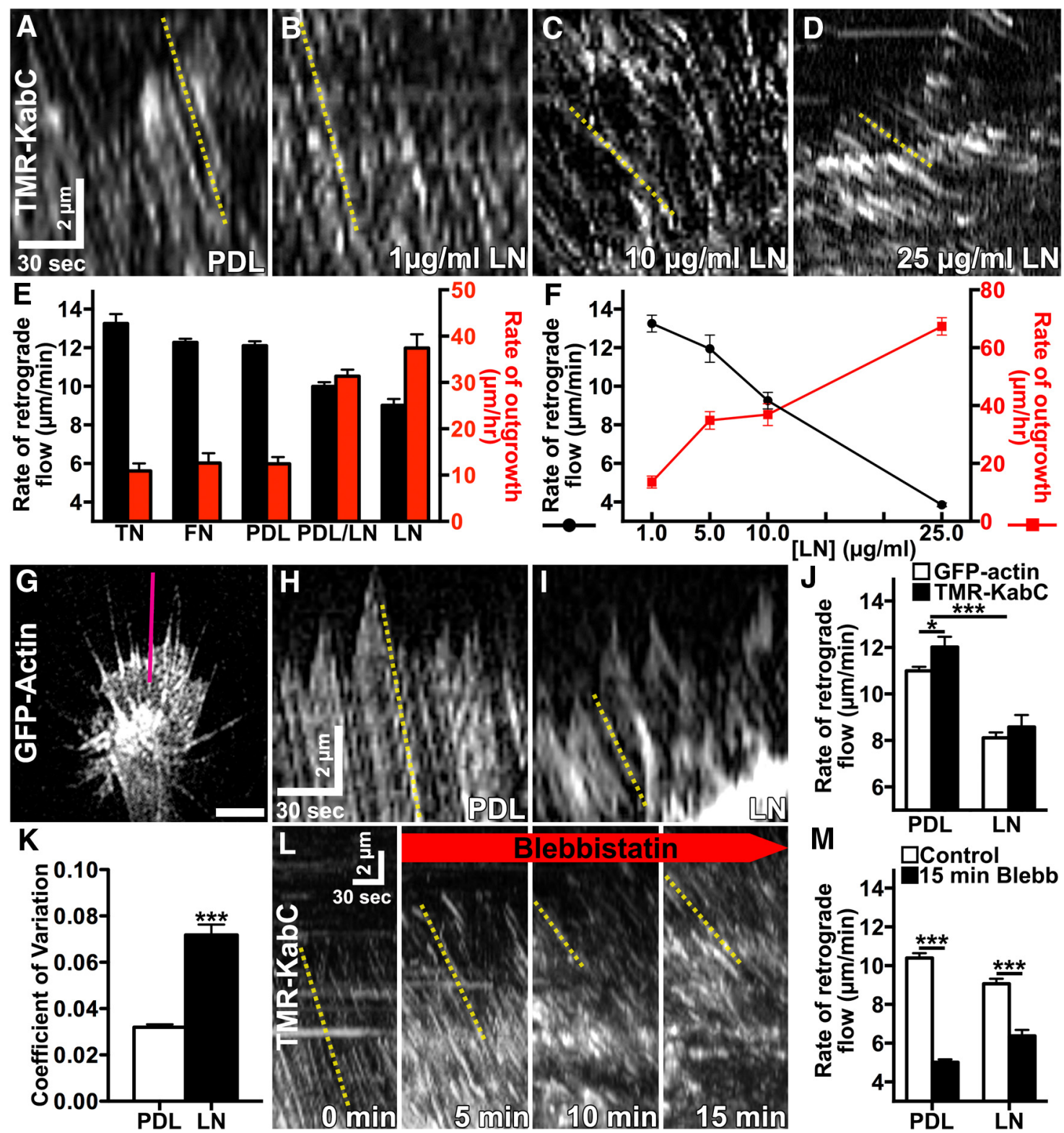

Figure 1. The rate of axon outgrowth is inversely proportional to actin retrograde flow (RF) rates. $\boldsymbol{A}-\boldsymbol{D}$, Actin RF in motile growth cones was visualized by TIRF microscopy using TMR-KabC, a barbed-end binding actin probe. Kymographs were generated from 2 min time-lapse sequences of TMR-KabC-labeled growth cones cultured on indicated substrata. Dashed yellow lines indicate example lines used to calculate flow rates. $E$, The rate of RF (left axis) and axon outgrowth (right axis) is inversely related for spinal neurons plated on different substrata: PDL ( $n=16 \mathrm{growth}$ cones, 68 axons), $10 \mu \mathrm{g} / \mathrm{ml} \mathrm{LN} \mathrm{(} n=15$ growth cones, 95 axons), PDL plus LN ( $n=16$ growth cones, 185 axons), $10 \mu \mathrm{g} / \mathrm{ml} \mathrm{FN} \mathrm{(} n=16$ growth cones, 70 axons), and $5 \mu \mathrm{g} / \mathrm{ml} \mathrm{TN} \mathrm{(} n=8 \mathrm{growth}$ cones, 37 axons). $\boldsymbol{F}$, Rate of RF (left axis) and axon outgrowth (right axis) axis is inversely related for neurons plated on increasing concentrations of LN: $1 \mu \mathrm{g} / \mathrm{ml}$ ( $n=11$ growth cones, $80 \mathrm{axons}), 5 \mu \mathrm{g} / \mathrm{ml}$ ( $n=9$ growth cones, 101 axons), $10 \mu \mathrm{g} / \mathrm{ml}$ ( $n=10$ growth cones, 63 axons), and $25 \mu \mathrm{g} / \mathrm{ml}$ ( $n=12$ growth cones, 249 axons). G, $2 D$ image of a GFP-actin-expressing growth cone on PDL with kymograph sample line through leading edge (red line). Scale bar, $5 \mu \mathrm{m}$. $\boldsymbol{H}-\boldsymbol{I}$, Kymographs were created from growth cones on PDL $(\boldsymbol{H})$ and $10 \mu \mathrm{g} / \mathrm{mI} \mathrm{LN}(\boldsymbol{I}) . J$, Growth cones labeled with TMR-KabC and GFP-actin exhibited significantly lower RF rates on LN ( $n=17$ growth cones) relative to PDL ( $n=20$ growth cones). $\boldsymbol{K}$, Coefficient of variation (SD/mean) of TMR-KabC RF is significantly greater for growth cones plated on $10 \mu \mathrm{g} / \mathrm{ml} \mathrm{LN}(n=137)$ versus PDL $(n=105)$. L, Kymographs generated from 2 min time-lapse sequences of TMR-KabC-labeled growth cones captured at the indicated times before and after $50 \mu$ m blebbistatin treatment. $\boldsymbol{M}$, Rate of RF after blebbistatin treatment was significantly attenuated on PDL ( $n=9$ growth cones) and LN ( $n=8$ growth cones) ${ }^{* * *} p<$ 0.001 ), but the percentage reduction (data not shown) was more significantly reduced in growth cones on $\operatorname{PDL}(p<0.001) .{ }^{* * *} p<0.001 ;{ }^{*} p<0.05$.

provides traction forces necessary to oppose both rearward myosin-motor-dependent actin filament contractility and actin filament polymerization, which drives leading edge protrusion (Choi et al., 2008; Gardel et al., 2008; Yamashiro and Watanabe, 2014). However, interactions between growth cone point contacts and the actin cytoskeleton during axon extension and guidance remain poorly understood.

Complex mechanisms regulate filamentous actin (F-actin) in the growth cone peripheral domain to influence growth cone morphology and movement. The F-actin network is governed by a balance between F-actin barbed-end polymerization and pointed-end depolymerization (Lowery and Van Vactor, 2009; Dent et al., 2011). Leading edge actin polymerization pushes membranes forward with some resistance (Symons and Mitchison, 1991; Lin et al., 1996; Mogilner and Oster, 2003; Carlier and Pantaloni, 2007). The resistive force of the membrane on F-actin polymerization, together with barbed-end directed myosin-II contractility, powers F-actin retrograde flow (RF) from the growth cone periphery to the central domain (Bamburg, 1999; Forscher and Smith, 1988; Lin and Forscher, 1995; Brown and 

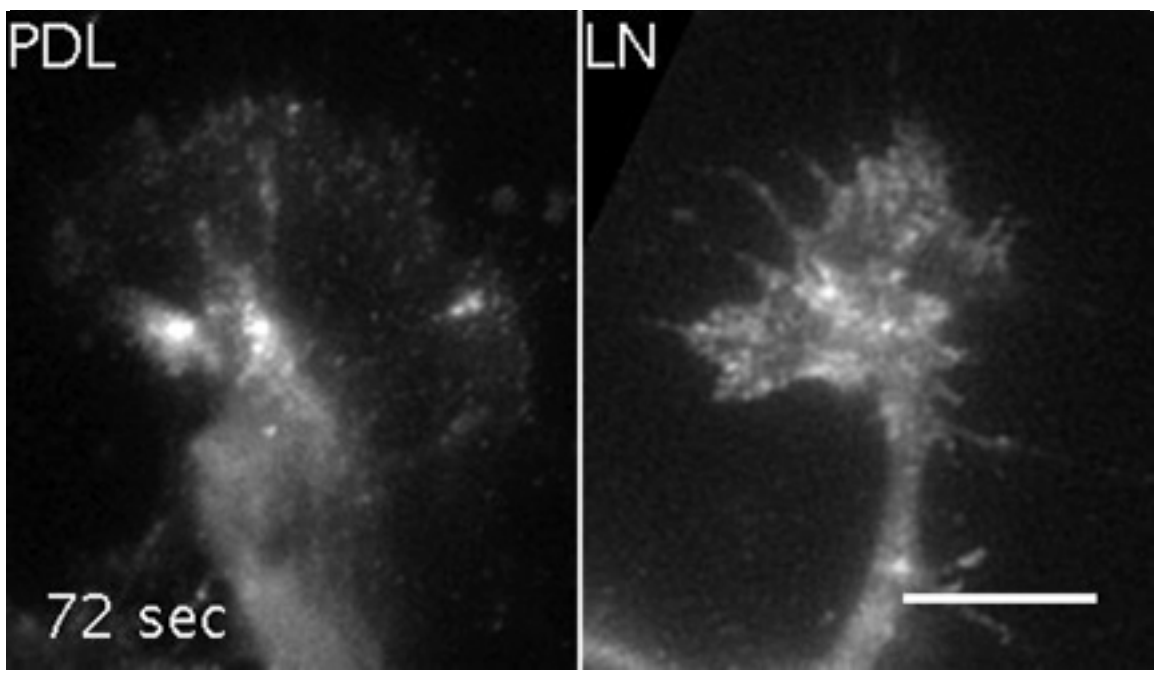

Movie 1. KabC-labeled growth cones on PDL and LN. Time-lapse TIRFimage sequence acquired with a $100 \times$ objective of growth cones on PDL and LN labeled with TMR-KabC. Images were captured at 2 s intervals for $2 \mathrm{~min}$. Playback is 7 frames/s. Scale bar, $5 \mu \mathrm{m}$.

Bridgman, 2003; Marsick et al., 2010; Flynn et al., 2012; Zhang et al., 2012). The balance among actin polymerization, myosin-IIdriven $\mathrm{RF}$, and ADF-cofilin depolymerization controls F-actin treadmilling in the growth cone peripheral domain (Mogilner and Oster, 2003; Turney and Bridgman, 2005; Zhang et al., 2012). In non-neuronal cells, focal adhesions slow actin treadmilling by linking rearward F-actin flow to adhesion receptors (Smilenov et al., 1999; Giannone et al., 2009; Thievessen et al., 2013). Slowing or "clutching" of RF at focal adhesions increases the ability of F-actin polymerization to generate membrane protrusion and forward cell translocation (Smilenov et al., 1999; Giannone et al., 2009; Thievessen et al., 2013). Clutching of RF is thought to regulate the rate of axon extension (Bard et al., 2008; Shimada et al., 2008; Toriyama et al., 2013), but it is not known whether local regulation of RF also directs axon guidance. Recent evidence from us and others has shown that the rate of RF has an inverse relationship with the rate of growth cone advance (Lin and Forscher, 1995, Santiago-Medina et al., 2013, Shimada et al., 2008, Toriyama et al., 2013, Kubo et al., 2015). However, it is unclear how RF rate depends on cell substratum or whether local differences may be responsible for axon guidance behaviors.

Here, we show that RF is reduced in rapidly migrating growth cones on laminin (LN) compared with less motile, non-integrinbinding poly-D-lysine (PDL). Moreover, acute stimulation with LN leads to accelerated axon outgrowth over a time course that correlates with point contact formation and reduced RF. We confirm that integrin receptor binding is both necessary and sufficient to slow RF through gain- and loss-of-function manipulations. Moreover, we show that RF can be locally restrained within growth cones at integrin adhesion sites. We also suggest a role for RF in regulating axon guidance using a substratum stripe assay. Finally, we show that soluble guidance cues that promote assembly or disassembly of point contacts regulate RF accordingly. These data suggest that regulation of clutching at point contacts is an important mechanism in axon guidance. Local differences in clutching forces at point contact adhesions may guide growth cone movements by slowing retrograde flow locally.

\section{Materials and Methods}

Plasmid constructs and reagents. GFP- $\gamma$-actin (rat) was provided by Andrew Matus (Friedrich Miescher Institute). Paxillin-GFP (chicken) was provided by A.F. Horwitz (University of Virginia, Charlottesville). Yellow fluorescent protein-Src homology-2 domain (dSH2) was provided by Benjamin Geiger (Weizmann Institute, Rehovot, Israel) and converted to GFP-dSH2 (Robles et al., 2005). Td-Tomato tractin was provided by Erik Dent (University of Wisconsin, Madison). Most expression constructs were subcloned into the Xenopus-preferred pCS2+ vector for mRNA synthesis using Gateway (Dave Turner, University of Michigan, Ann Arbor). To visualize actin retrograde flow, neuronal cultures were incubated in $100 \mathrm{pm}$ tetramethylrhodamineconjugated kabiramide-C (TMR-KabC, kind gift from Gerard Marriott, University of California, Berkeley) for $3 \mathrm{~min}$, then washed with $1 \times$ modified Ringer's solution. Blebbistatin (SigmaAldrich) was used as a selective inhibitor of non-muscle myosin-II. Heparin (Sigma-Aldrich) was used to block binding of soluble LN to PDL (Sigma-Aldrich)-coated coverslips.

Embryo injection and cell culture. Xenopus laevis embryos were obtained as described previously (Gómez et al., 2003) and staged according to Nieuwkoop and Faber (1994). For protein expression experiments, two dorsal blastomeres of 8-cell-stage embryos were injected with 0.25 $0.5 \mathrm{ng}$ of GFP-dSH2 in vitro-transcribed, capped mRNA (mMessage Machine; Ambion), or 60-80 pg of paxillin-GFP (PXN-GFP), GFP- $\gamma$-actin, or Td-Tomato tractin DNA. Neural tubes were dissected from 1-d-old embryos and explant cultures containing a heterogeneous population of spinal neurons were prepared as described previously (Gómez et al., 2003). Explants were plated onto acid-washed no. 1.5 glass coverslips coated with $50 \mu \mathrm{g} / \mathrm{ml} \mathrm{PDL}, 10 \mu \mathrm{g} / \mathrm{ml} \mathrm{LN}$ (Sigma-Aldrich), $10 \mu \mathrm{g} / \mathrm{ml}$ fibronectin (FN; Sigma-Aldrich), and $5 \mu \mathrm{g} / \mathrm{ml}$ tenascin (TN; Millipore). To visualize LN adsorption to the substratum, PDL-coated coverslips were treated with $25 \mu \mathrm{g} / \mathrm{ml}$ fluorescent LN (HiLyte 488; Cytoskeleton) for $15 \mathrm{~min}$ and then washed with PBS (Sigma-Aldrich) before imaging. To block LN adsorption, coverslips were pretreated with $2 \mu \mathrm{g} / \mathrm{ml}$ heparin (Sigma-Aldrich) for $15 \mathrm{~min}$, followed by $25 \mu \mathrm{g} / \mathrm{ml}$ fluorescent $\mathrm{LN}$ with heparin for $15 \mathrm{~min}$. Cultures were imaged or fixed $16-24 \mathrm{~h}$ after plating. All methods were approved by the University of Wisconsin School of Medicine Animal Care and Use Committee.

Stripe assay. Silicone masks (Karlsruhe Institute of Technology, Karlsruhe, Germany) with 90 - $\mu$ m-wide parallel lanes were attached to acid-washed coverslips. A solution of $10 \mu \mathrm{g} / \mathrm{ml} \mathrm{LN}$ with $50 \%$ HiLyte 488 LN (to detect border in live cultures) was passed through the channels and allowed to bind for $1 \mathrm{~h}$, and then rinsed with excess PBS to remove unbound protein. After the mask was removed, $50 \mu \mathrm{g} / \mathrm{ml}$ PDL was applied to the entire coverslip for $45 \mathrm{~min}$. Patterned substrata were used immediately for spinal explant cultures. After 18-24 h, cultures with explants near the LN-PDL border were loaded with TMR-KabC. Alexa Fluor-546 phalloidin (1:100; Invitrogen) to label F-actin.

Image acquisition and analysis. For both live and fixed fluorescence microscopy, high-resolution images were acquired using either a $60 \times /$ 1.45 numerical aperture (NA) objective lens on an Olympus Fluoview 500 laser-scanning confocal system mounted on an AX-70 upright microscope or a $100 \times / 1.5 \mathrm{NA}$ objective lens on a Nikon total internal reflection fluorescence (TIRF) microscope. For in vivo imaging, highresolution images were acquired using a $60 \times / 1.1 \mathrm{NA}$ water-immersion objective lens on the confocal. On the confocal microscope, samples were imaged at $2-2.5 \times$ zoom (pixel size $=165-200 \mathrm{~nm}$ ). Images were collected on the TIRF with a Coolsnap HQ2 camera (Roper Scientific) using $2 \times 2$ binning (pixel size $=127 \mathrm{~nm}$ ). For bright-field time-lapse microscopy, low-magnification phase-contrast images were acquired using a $20 \times$ objective on a Nikon microscope equipped with an $x-y$ motorized stage for multipositional imaging. Multipositional images were captured at $1 \mathrm{~min}$. intervals. Live explant cultures were sealed within perfusion chambers as described previously (Gómez et al., 2003) to allow rapid exchange of solutions. Images were analyzed using ImageJ software. 


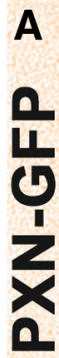
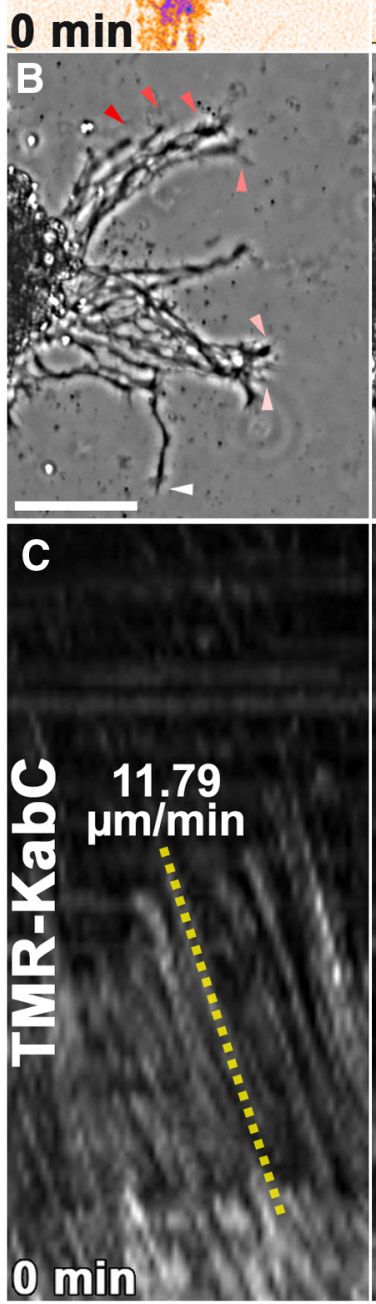

$10 \mathrm{~min}$

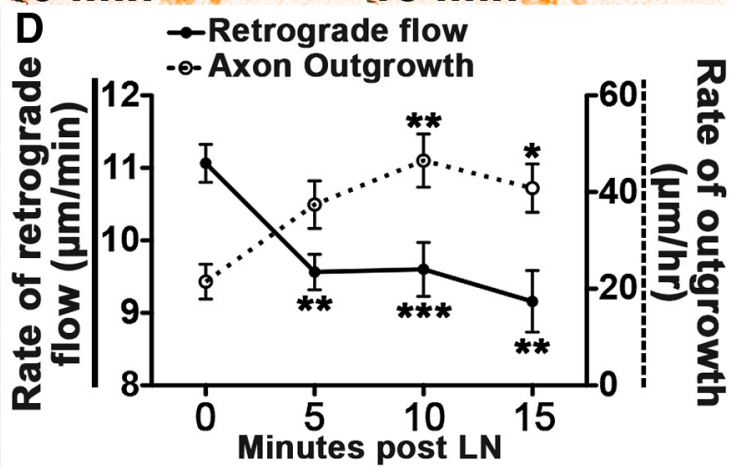

A"

$\mathbf{A}^{\prime \prime \prime}$

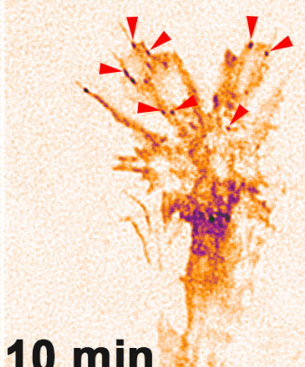

A'

$5 \mathrm{~min}$
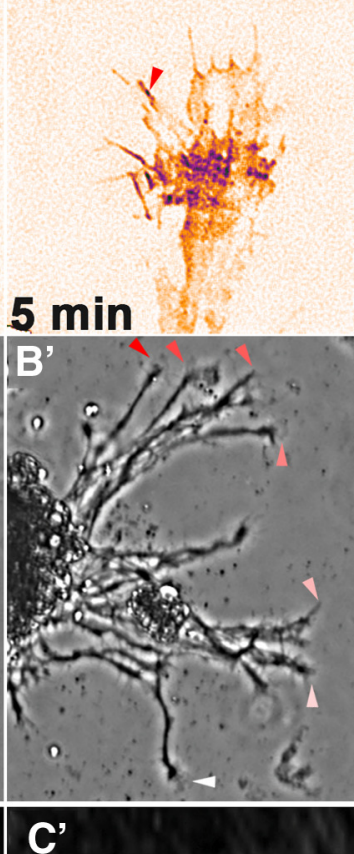

'

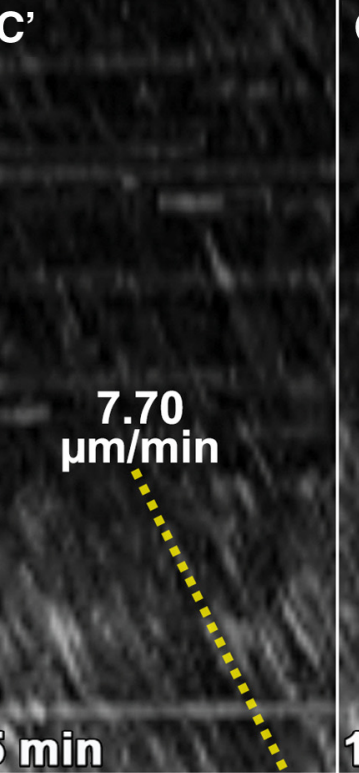

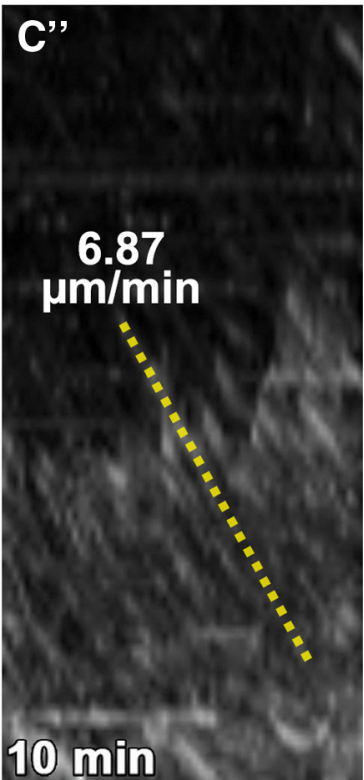

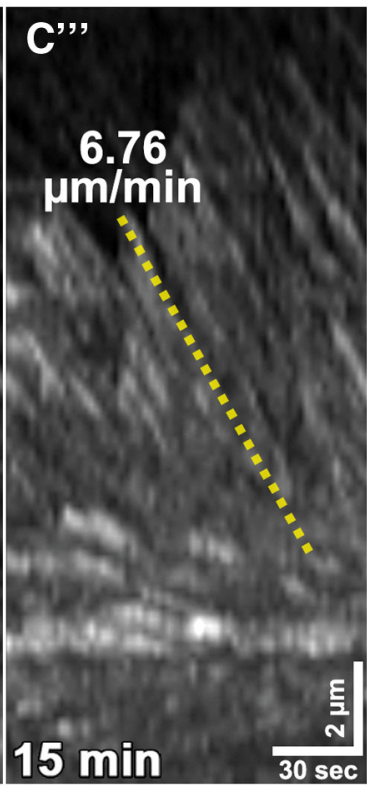

Figure 2. Acute LN stimulation accelerates axon outgrowth over a time course that correlates with point contact formation and reduced retrograde flow. $A-A^{\prime \prime \prime}$, Confocal images of a growth cone expressing PXN-GFP on PDL before and at indicated times after addition of $25 \mu \mathrm{g} / \mathrm{ml} \mathrm{LN}$. Within $10 \mathrm{~min}$ of LN addition, many point contact adhesions form (red arrowheads). Scale bar, $5 \mu \mathrm{m}$. $\boldsymbol{B}$, Low-magnification phase contrast images showing that most axons accelerate (color-matched arrowheads) after 15 min of treatment with $25 \mu \mathrm{g} / \mathrm{ml} \mathrm{LN}$. Scale bar, $50 \mu \mathrm{m}$. C, Kymographs generated from 2 min time-lapse sequences of TMR-KabC-labeled growth cones captured at indicated times before and after $L N$ addition. Dashed yellow lines indicated the calculated example flow rates. $D$, Average rate of axon outgrowth $(n=56)$ versus retrograde flow ( $n=10$ growth cones) at times before and after $L N$ stimulation shows an inverse relationship. ${ }^{* * *} p<0.001 ;{ }^{* *} p<0.01 ;{ }^{*} p<0.05$.

Point contacts were identified as discrete areas containing PXN-GFP or GFP-dSH2 that were at least two times brighter than the surrounding background and remained fixed in place for a minimum of $30 \mathrm{~s}$. (Woo and Gómez, 2006). For display purposes, some images were pseudocolored. TMR-KabC-labeled growth cones were imaged at $2 \mathrm{~Hz}$ by TIRF microscopy for 2 min to measure actin RF. TMR-KabC RF rates were quantified by kymography by sampling three to seven lines per growth cone along filopodia and radiating equally around the axis of outgrowth. We find that kymography is the most accurate method to measure RF, but recognize that it is limited to linear F-actin movements. Whereas off-axis flow may slightly influence our absolute rate values, we expect that these movements will be consistent across experimental groups, so we believe that kymography does provide accurate relative differences. Moreover, RF measurements made in vivo were performed on relatively flat growth cones with the confocal pinhole aperture set to one Airy unit, which provides an optical section of $600-700 \mathrm{~nm}$, depending on the fluorophore. At this optical section depth, axial position changes of actin puncta will have a minimal effect on RF rate calculations. Statistical analysis was performed using Prism software. Analysis was completed with an unpaired Student's $t$ test for comparison of two experimental groups or a one-way ANOVA with a Bonferroni's multiple-comparison test for comparison of three or more experimental groups. For comparisons of the percentage change in RF, SE was calculated as posttreatment $\mathrm{SD}$ divided by pretreatment mean. 


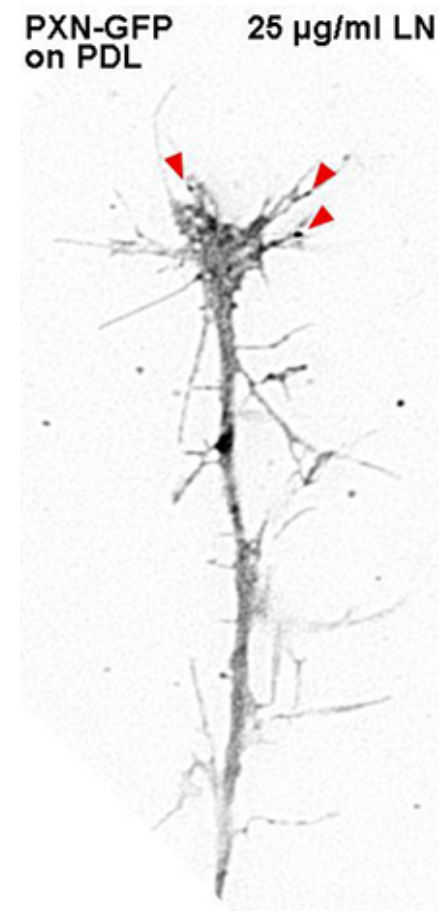

$1275 \mathrm{sec}$

Movie 2. PXN-GFP-expressing growth cone on PDL with acute LN stimulation. Time-lapse confocal image sequence acquired with a $60 \times$ objective with 2.5 zoom of a growth cone on PDL expressing PXN-GFP acutely stimulated with LN, which induces the formation of stable PXN-GFP labeled point contacts (red arrows). Images were captured at $15 \mathrm{~s}$ intervals for $5 \mathrm{~min}$ before LN stimulation and $30 \mathrm{~min}$ after LN stimulation. Playback is 7 frames/s.

Dynamic adhesion maps. Dynamic adhesion map images were prepared from image stacks as detailed previously (Santiago-Medina et al., 2012). Briefly, an image stabilization algorithm was applied if necessary and, to improve edge detection, an unsharp mask routine was applied, followed by thresholding to highlight the puncta of interest. Next, an 8-bit binary filter was applied to equalize point contact intensities. Image stacks were then converted to 16-bit and user-defined subsets were summed so that intensity encoded pixel lifetime. Final images were contrast enhanced and pseudocolorized.

\section{Results}

Rates of axon outgrowth and actin retrograde flow are inversely proportional and substratum-dependent

We have shown previously that growth cone point contact adhesion dynamics regulate the rate and direction of axon outgrowth (Woo and Gómez, 2006; Myers et al., 2011). Point contacts are thought to support forward axonal translocation in part by stabilizing leading edge protrusions. However, point contacts contain a number of adaptor proteins that link integrin receptors to the actin cytoskeleton (Woo and Gómez, 2006; Myers et al., 2011; Myers et al., 2011), which may further support axon extension by clutching RF. To test whether point contacts correlate with RF, we first determined the rates of RF in Xenopus spinal neuron growth cones on different substrata. We have shown previously that the culture substratum governs point contact assembly and dynamics in Xenopus spinal neuron growth cones (Robles and Gómez, 2006), which may correlate with clutching of RF. We cultured spinal neurons on $50 \mu \mathrm{g} / \mathrm{ml} \mathrm{PDL} ; 1,5,10$ and $25 \mu \mathrm{g} / \mathrm{ml} \mathrm{LN}$; PDL plus $10 \mu \mathrm{g} / \mathrm{ml}$ $\mathrm{LN} ; 10 \mu \mathrm{g} / \mathrm{ml} \mathrm{FN}$; or $5 \mu \mathrm{g} / \mathrm{ml} \mathrm{TN}$, which are conditions that support point contact adhesion formation to varying degrees (Robles and Gómez, 2006) and associated axon outgrowth rates (Fig. 1). Axon outgrowth rates were quantified over a 30 min time period using low-magnification phase contrast imaging.

To investigate the effect of substratum adhesion on RF, we used TMR-KabC (Petchprayoon et al., 2005), a small, cellpermeable molecule that binds to the barbed ends of F-actin and has been used previously at low doses to track RF (Keren et al., 2008; Santiago-Medina et al., 2012, 2013). To speckle the barbed ends of actin filaments, we treated neurons for $3 \mathrm{~min}$ with 100 pM TMR-KabC, which partially labels actin barbed ends, but does not affect the basal rate of neurite outgrowth or growth cone morphology (Santiago-Medina et al., 2013). Immediately after TMR-KabC labeling, we imaged growth cones on each substratum at $2 \mathrm{~Hz}$ by TIRF microscopy for $2 \mathrm{~min}$. F-actin RF rates were quantified by kymography by sampling three to seven lines per growth cone radiated equally from the axis of outgrowth (Fig. $1 A-D$; see Materials and Methods). This analysis showed a substratum-dependent, inverse relationship between RF rates and axon outgrowth. Growth cones on LN, which assemble many point contacts and extend rapidly (Robles and Gómez, 2006), have significantly lower RF rates compared with growth cones plated on PDL, FN, and $\mathrm{TN}$, which assemble few or no point contacts and extend slowly (Fig. 1E, Movie 1). We also found that RF and axon outgrowth rates varied with LN substratum concentration (Fig. $1 F$ ), suggesting that higher ligand density, which promotes point contact assembly (data not shown), clutches RF to enhance axon outgrowth. We confirmed the differential RF rates on PDL versus LN by imaging GFP-actin speckles in Xenopus spinal neurons (Fig. $1 G-I$ ). It is noteworthy that the rates of RF measured with GFP-actin were slightly but significantly slower compared with RF measured using TMR-KabC for neurons on PDL (Fig. 1J), which may be due to partial inhibition of actin polymerization by fluorescent actin fusion proteins (Riedl et al., 2008). In addition to rates of RF, we also found that RF on LN was significantly more variable compared with RF on PDL (Fig. $1 K$ ). These results suggest that dynamic and local clutching during point contact formation, stabilization, and turnover may regulate the rate of RF differentially within growth cone subdomains. Adhesion proteins such as talin, $\alpha$-actinin, paxillin, and vinculin likely contribute to these linkages (Woo and Gómez, 2006; Myers et al., 2011; Myers et al., 2011). Together, these results suggest that point contacts within the growth cone periphery serve two functions: (1) point contacts stabilize new protrusions to prevent retraction mediated by contractile forces (previous data) and (2) point contacts clutch RF to allow actin polymerization to drive further membrane protrusion (this work).

Leading edge RF in growth cones is believed to be significantly powered by myosin-II-motor-mediated F-actin contraction, with some contribution by actin polymerization-mediated pushing forces against the leading edge plasma membrane (Lin et al., 1996; Bridgman et al., 2001; Brown and Bridgman, 2003; Mogilner et al., 2003; Medeiros et al., 2006; Craig et al., 2012). Consistent with this notion, treatment of Aplysia growth cones with the myosin ATPase inhibitor blebbistatin slows the rate of RF by one-half, which is further attenuated by actin depolymerization with cytochalasin D (Medeiros et al., 2006). However, myosin-II also contributes to point contact formation in growth cones on LN because blebbistatin reduces growth cone point contact size and number (Woo and Gómez, 2006). Therefore, we hypothesized that myosin-II inhibition would affect RF less on LN com- 
pared with PDL because inhibition of myosin-II would be counterbalanced by loss of point contacts on LN. We examined the effects of myosin-II inhibition by imaging TMR-KabC-labeled growth cones on PDL (Fig. 1L) and LN (data not shown) for 2 min intervals every $5 \mathrm{~min}$ after acute treatment with $50 \mu \mathrm{m}$ blebbistatin over a $15 \mathrm{~min}$ period. Inhibition of myosin-II in growth cones on PDL reduced RF to $<50 \%$ of basal rates after 15 min (Fig. 1M). As hypothesized, the effects of blebbistatin were more modest in growth cones on LN (Fig. 1M), consistent with the counteracting effects of reduced clutching by point contacts. This analysis also validates TMR$\mathrm{KabC}$ as an accurate probe to measure myosin-II-mediated RF.

\section{Acute LN stimulation accelerates axon outgrowth over a time course that correlates with point contact formation and reduced retrograde flow}

To link point contact assembly temporally with clutching of RF and acceleration of axon outgrowth, we acutely stimulated neurons on PDL with LN. We have shown previously in neurons cultured on PDL that growth cone point contacts form and neurite outgrowth accelerates rapidly in response to acute LN stimulation over a time course that follows LN binding to the substratum (Woo and Gómez, 2006). To confirm this, we imaged PXN-GFPexpressing neurons on PDL by TIRF microscopy and observed the assembly of point contacts and accelerated axon outgrowth after 15 min of treatment with 25 $\mu \mathrm{g} / \mathrm{ml} \mathrm{LN}$ (Fig. 2A, Movie 2). The time course for the increased rate of neurite outgrowth was quantified with lowmagnification phase contrast imaging (Fig. 2B). Next, Xenopus spinal neurons loaded with TMR-KabC were treated acutely with $25 \mu \mathrm{g} / \mathrm{ml} \mathrm{LN}$ and imaged for $2 \mathrm{~min}$ at $2 \mathrm{~Hz}$ every 5 min after LN treatment (Movie 3). Analysis of the rate of RF in growth cones by kymography (Fig. 2C) shows that RF slows within 5 min after LN treatment in a temporal pattern that mirrors the de novo assembly of point con-

tacts and accelerated neurite outgrowth (Fig. 2D). This temporal correlation supports the notion that mechanical coupling between point contact adhesions and actin filaments, through a molecular clutch, slows retrograde flow and promotes axon elongation.

To confirm that the assembly of point contacts is necessary to reduce $\mathrm{RF}$ in response to an immobilized $\mathrm{LN}$ substratum, we used coapplication of heparin to block adsorption of LN to the culture surface. This experiment dissociates the effects of soluble LN versus an immobilized LN substratum. Heparin is a negatively charged, heavily sulfated glycosaminoglycan that has been used

\section{TMR-KabC} $5 \mathrm{~min}$ LN
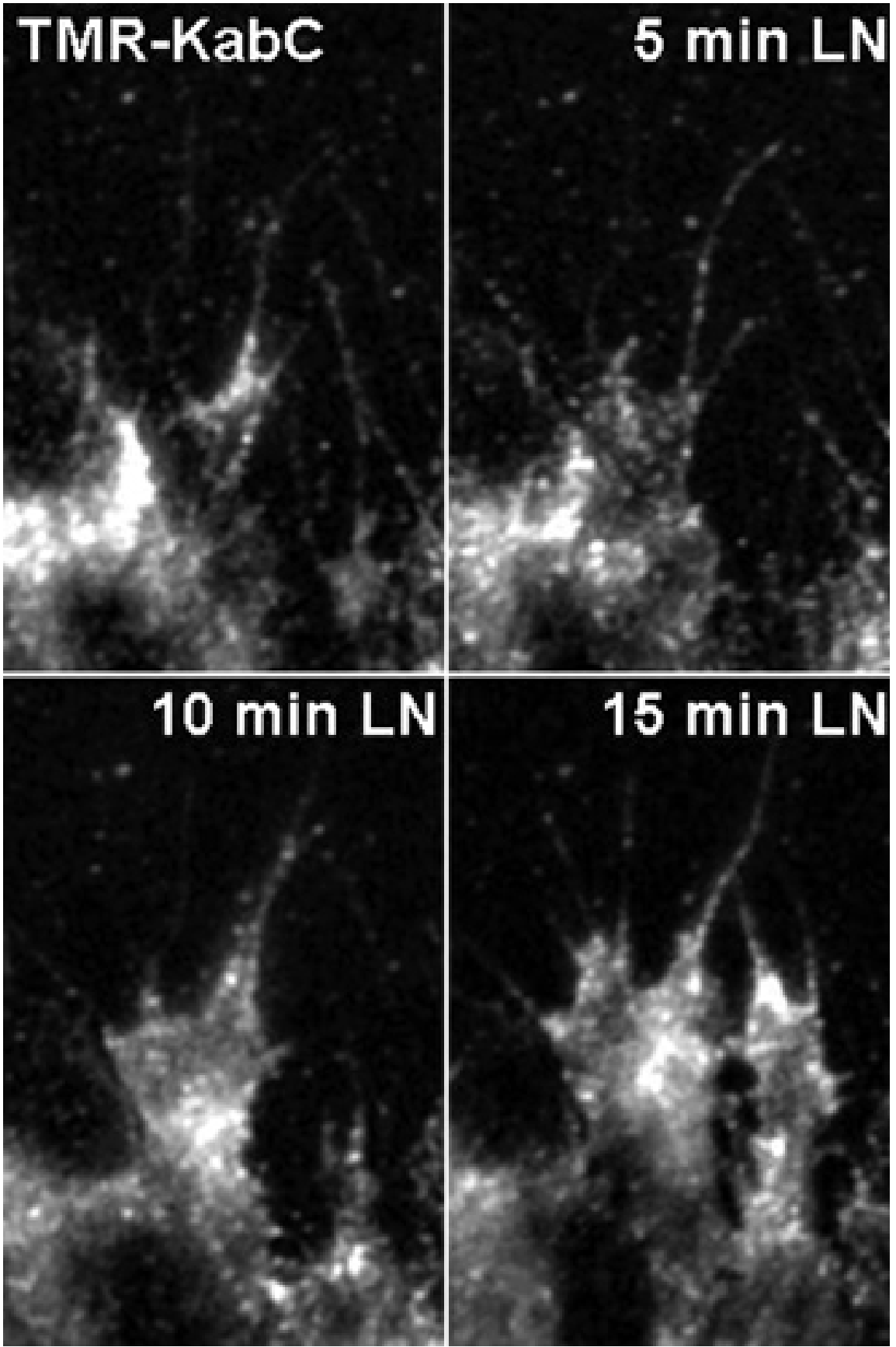

Movie 3. KabC-labeled growth cones on PDL with acute LN stimulation. Time-lapse TIRF image sequence acquired with a $100 \times$ objective of a growth cone on PDL labeled with TMR-KabC acutely stimulated with LN. Growth cones were imaged 5 min pre-LN and at 5, 10, and 15 min post-LN. This image sequence includes the growth cone used to generate kymographs depicted in Figure $2 C$. Images were captured at $2 \mathrm{~s}$ intervals for $2 \mathrm{~min}$. Playback is $7 \mathrm{frames} / \mathrm{s}$.

to prevent nonspecific adsorption of Netrin to surfaces, but not specific interactions of Netrin with its cell surface receptors (Moore et al., 2012). Because LN contains a heparin-binding site localized to the $\beta$-chain and the integrin binding region is localized to the $\alpha$-chain, we hypothesized that pretreatment of neurons with heparin would not inhibit LN activation of integrin receptors (Beck et al., 1990). We first tested whether we could block the adsorption of LN to a PDL substratum with pretreatment of $2 \mu \mathrm{g} / \mathrm{ml}$ heparin. When not preblocked, we found that soluble LN binds rapidly to a PDL substratum and approaches saturation within 10-15 min (Fig. 3A) (Woo and Gómez, 2006). 


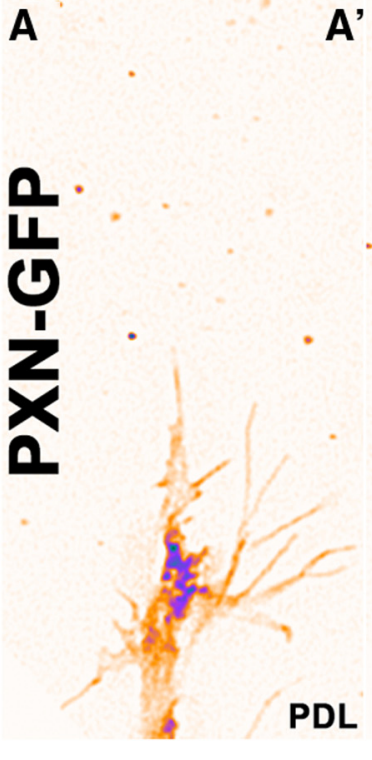

B

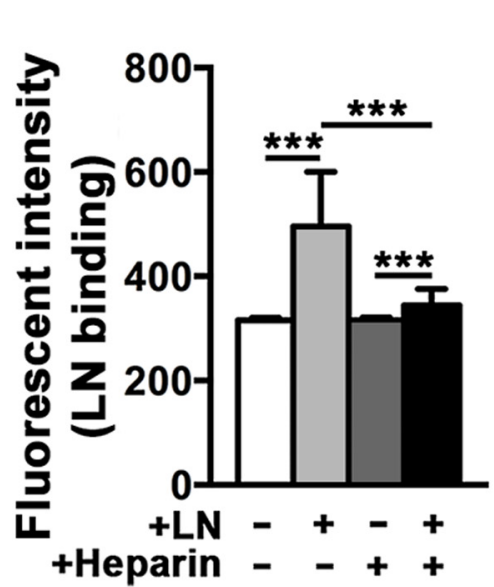

15 min Post LN

C

D D'
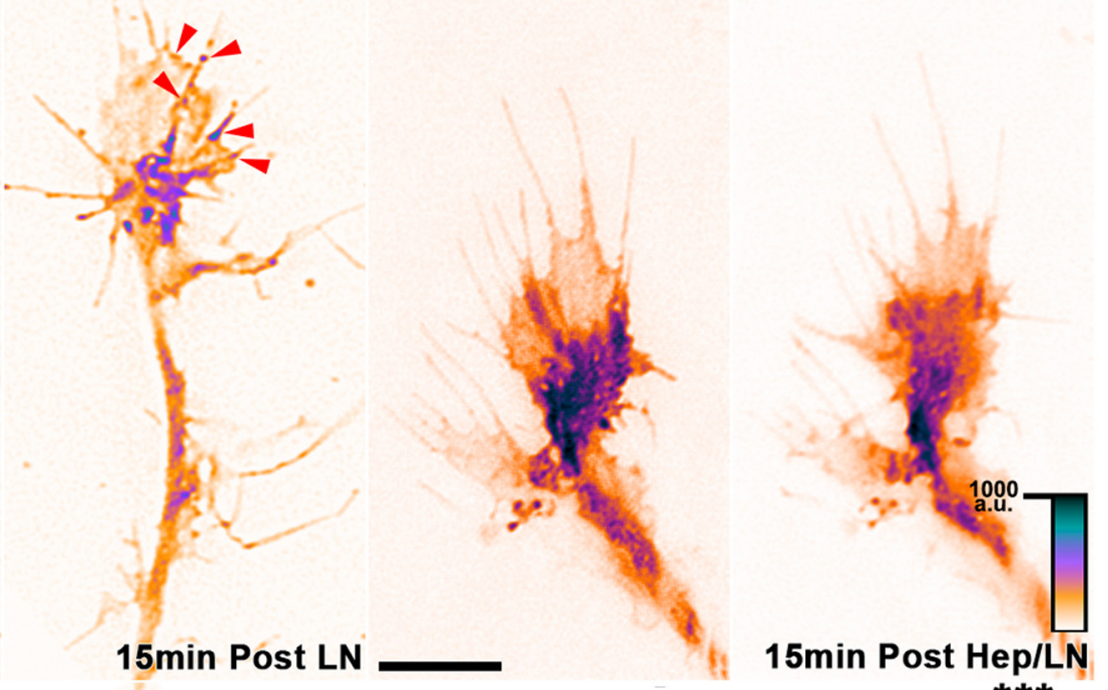

15min Post Hep/LN
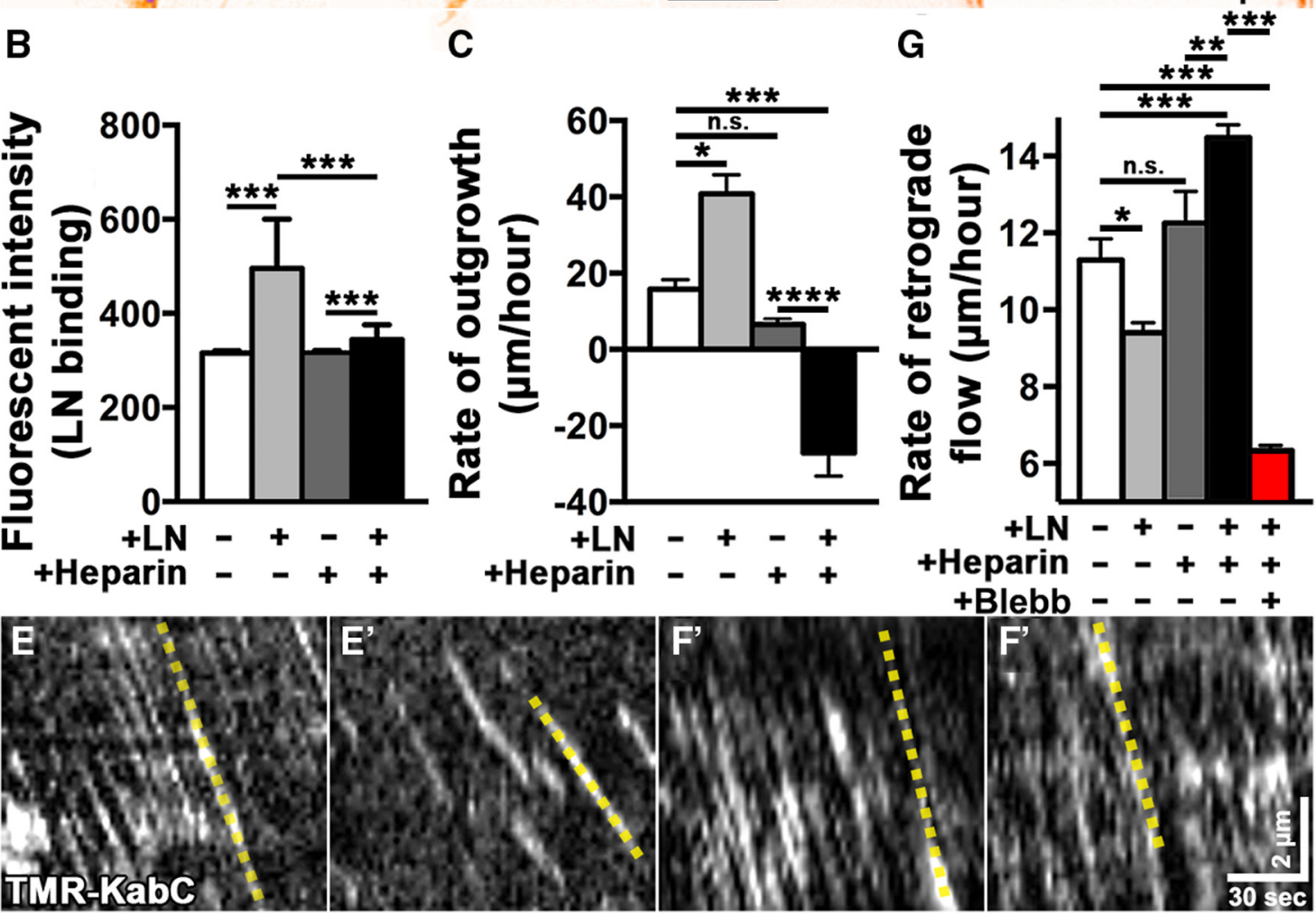

Figure 3. Point contact formation is required for $L N$ induced axon outgrowth. $\boldsymbol{A}, \boldsymbol{A}^{\prime}$, TIRF images of PXN-GFP expressing growth cone on PDL before $(\boldsymbol{A})$ and 15 min after addition of $L N\left(\boldsymbol{A}^{\prime}\right)$. $\boldsymbol{B}$, Mean intensity of fluorescent LN on PDL-coated glass coverslips treated for $15 \mathrm{~min}$ with $25 \mu \mathrm{g} / \mathrm{ml} \mathrm{LN}$ alone, $2 \mu \mathrm{g} / \mathrm{ml}$ heparin alone, and LN plus heparin. $C$, Axon outgrowth on PDL $(n=80)$ is stimulated by 15 min treatment with $L N(n=52)$, butisstrongly inhibited by soluble $L N(L N$ plus heparin, $n=25) \cdot \boldsymbol{D}, \boldsymbol{D}^{\prime}$, TIRF images of PXN-GFP expressing growth cone on PDL before $(\boldsymbol{D})$ and 15 min after $\left(\boldsymbol{D}^{\prime}\right)$ the addition of $L N$ plus heparin. $\boldsymbol{E}, \boldsymbol{F}$, Kymographs generated from 2 min time-lapse sequences of TMR-KabC-labeled growth cones on PDL before $(\boldsymbol{E}, \boldsymbol{F})$ and after stimulation with $L N\left(\boldsymbol{E}^{\prime}\right)$ and $L N$ plus heparin $\left(\boldsymbol{F}^{\prime}\right)$. Dashed yellow lines indicate example lines used to calculate flow rates. G, Average rates of TMR-KabC retrograde flow (RF) in growth cones plated on PDL before and 15 min after indicated stimulations. Adsorbed LN significantly slows RF, whereas soluble LN significantly accelerates RF ( $n=9$ growth cones). Scale bar, $5 \mu \mathrm{m}$. ${ }^{* * *} p<0.001 ;{ }^{* *} p<0.01 ;{ }^{*} p<0.05$.

Conversely, pretreatment with $2 \mu \mathrm{g} / \mathrm{ml}$ heparin significantly inhibits LN binding (Fig. 3A). Next, we sought to determine how bound versus soluble LN affected axon outgrowth, point contact formation, and RF. As described previously, stimulation with LN for $15 \mathrm{~min}$ strongly promotes point contact formation (Fig. $3 B, C$ ) and axon extension (Figs. 3D). However, 15 min of treatment with soluble, nonadsorbed LN (heparin cotreatment; Fig. $3 E$ ) does not support point contact formation (Fig. 3C,E) nor axon extension (Fig. 3D) and often leads to axon stalling or re- traction (Fig. 3E, Movie 4). Therefore, soluble, nonabsorbed LN could activate cell signals that increase RF. For example, active Src is linked to actin polymerization (Tehrani et al., 2007), which may contribute to "pushing" of actin filaments rearward from the leading edge. Moreover, integrin receptors can activate RhoA (Woo and Gómez, 2006; Vicente-Manzanares et al., 2009) and downstream Rho-associated coiled coil-containing kinase (ROCK), which phosphorylates the myosin regulatory light chain at Ser19, resulting in myosin-II-mediated contractility of 


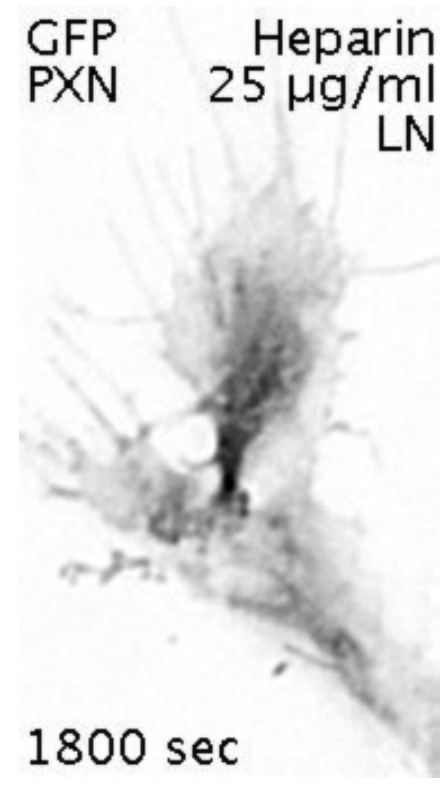

Movie 4. PXN-GFP-expressing growth cone on PDL with acute LN stimulation and pretreatment with Heparin. Time-lapse confocal image sequence acquired with a $60 \times$ objective with 2.5 zoom of a growth cone on PDL expressing PXN-GFP acutely stimulated with LN and heparin. This image sequence includes the growth cone used to generate kymographs depicted in Figure 3D. Images were captured at $15 \mathrm{sintervals}$ for $5 \mathrm{~min}$ before $\mathrm{LN}$ stimulation and $30 \mathrm{~min}$ after $\mathrm{LN}$ and heparin stimulation. Playback is 7 frames/s.

the actin network. Therefore, to determine how soluble LN influences RF, TMR-KabC-labeled neurons were first treated with 2 $\mu \mathrm{g} / \mathrm{ml}$ heparin, which alone does not significantly change RF. Interestingly, whereas RF significantly slows in response to substratum immobilized LN (Fig. $3 F, H$ ), the addition of soluble LN applied with heparin significantly increased RF (Fig. 3G,H). Consistent with the activation of RF without increased adhesion, addition of $\mathrm{LN}$ with heparin resulted in a robust retraction of many axons (Fig. 3D). To verify that soluble LN leads to downstream activation of myosin-II, we repeated the heparin and LN cotreatment experimental paradigm in the presence of $50 \mu \mathrm{g} / \mathrm{ml}$ blebbistatin and found that myosin-II inhibition blocked the increase of RF elicited by soluble LN (Fig. 3G). These data suggest that soluble LN activates actin network contractility. This result is in sharp contrast to bound LN, suggesting that, without clutching by point contacts, soluble LN strongly stimulates RF and induces axon retraction.

\section{Local clutching modulates actin retrograde flow at growth} cone point contacts

Growth cones are more dynamic and motile on LN compared with PDL and undergo cyclical periods of robust membrane protrusion and retraction. Leading edge protrusions are stabilized by new adhesion formation (Woo and Gómez, 2006; Myers et al., 2011; Myers et al., 2011; Santiago-Medina et al., 2013), whereas membrane retractions often occur in response to adhesion disassembly. Therefore, we investigated whether differences in rates of RF correlate with sites of leading edge protrusion versus retraction. As predicted, we found that the rate of RF was significantly slower during membrane protrusion (Fig. 4A) compared with a stationary leading edge (Fig. $4 B)$, but significantly faster during leading edge retraction (Figs. $4 C, D$ ). These results suggest that clutching of RF to point contact adhesions may direct axon outgrowth through local regulation of protrusion.

Growth cones on LN exhibit more variable RF rates compared with PDL (Fig. 1G), suggesting that local clutching by point contact adhesions may have a stronger influence on RF near adhesions. To determine whether RF rates differ near point contacts, we simultaneously imaged point contact adhesions with PXN-GFP or GFP-dSH2 (Robles and Gómez, 2006) together with TMR-KabC in Xenopus spinal neurons on LN (Fig. 4E, Movie 5). F-actin bundles that colocalized with stable point contacts ( $>1 \mathrm{~min}$ in duration) were used to gen-
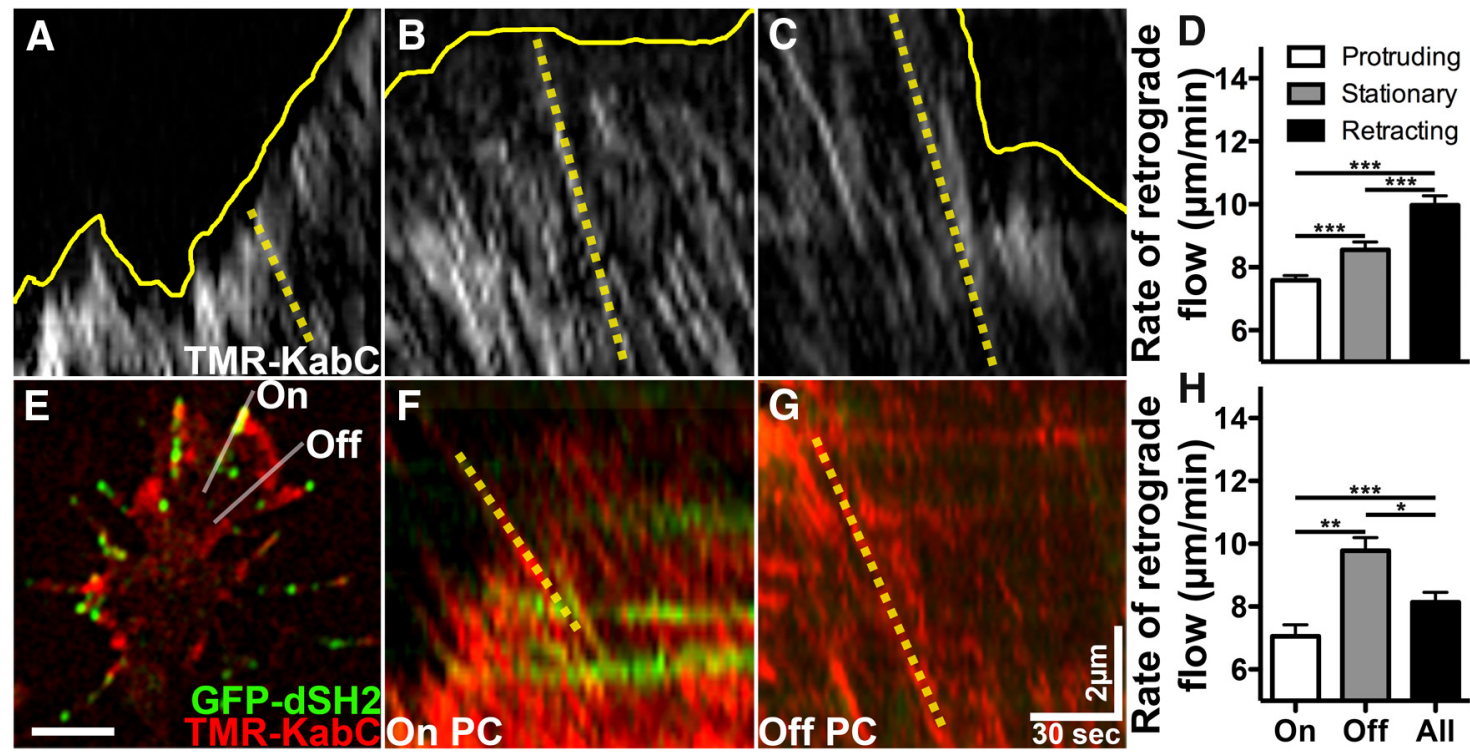

Figure 4. F-actin retrograde flow rates correlate with leading edge protrusion/retraction and is reduced at adhesion sites. $\boldsymbol{A}-\boldsymbol{C}$, Representative kymographs generated from regions of protruding $(\boldsymbol{A})$, stationary $(\boldsymbol{B})$, and retracting $(\boldsymbol{C})$ leading edge membrane. Dashed yellow lines indicated calculated example flow rates. Yellow line indicates growth cone leading edge. $\boldsymbol{D}$, Rate of retrograde flow (RF) is significantly slower in protruding relative to stationary and retracting membranes ( $n=15$ growth cones). $E$, 2D TIRF image of a growth cone expressing PXN-GFP (green) and labeled with TMR-KabC (red). Note the strong TMR-KabC labeling at the leading edge where F-actin barbed-ends are concentrated. $\boldsymbol{F}$, G, Kymographs generated from 2 min time-lapse sequences of TMR-KabC and PXN-GFP double-labeled growth cones using sampling lines over adhesions ( $\boldsymbol{F}$ ) and off adhesions ( $\boldsymbol{G})$. Horizontal green lines in $\boldsymbol{F}$ represent stable PXN-containing adhesions. $\boldsymbol{H}$, Average RF rates over adhesions $(n=38)$ are significantly slower than off adhesions $(n=25)$ and compared with randomly sampled $(n=63) \mathrm{RF}$ rates. Scale bar, $5 \mu \mathrm{m}$. ${ }^{* * *} p<0.001 ;{ }^{* *} p<0.01 ;{ }^{*} p<0.05$. 


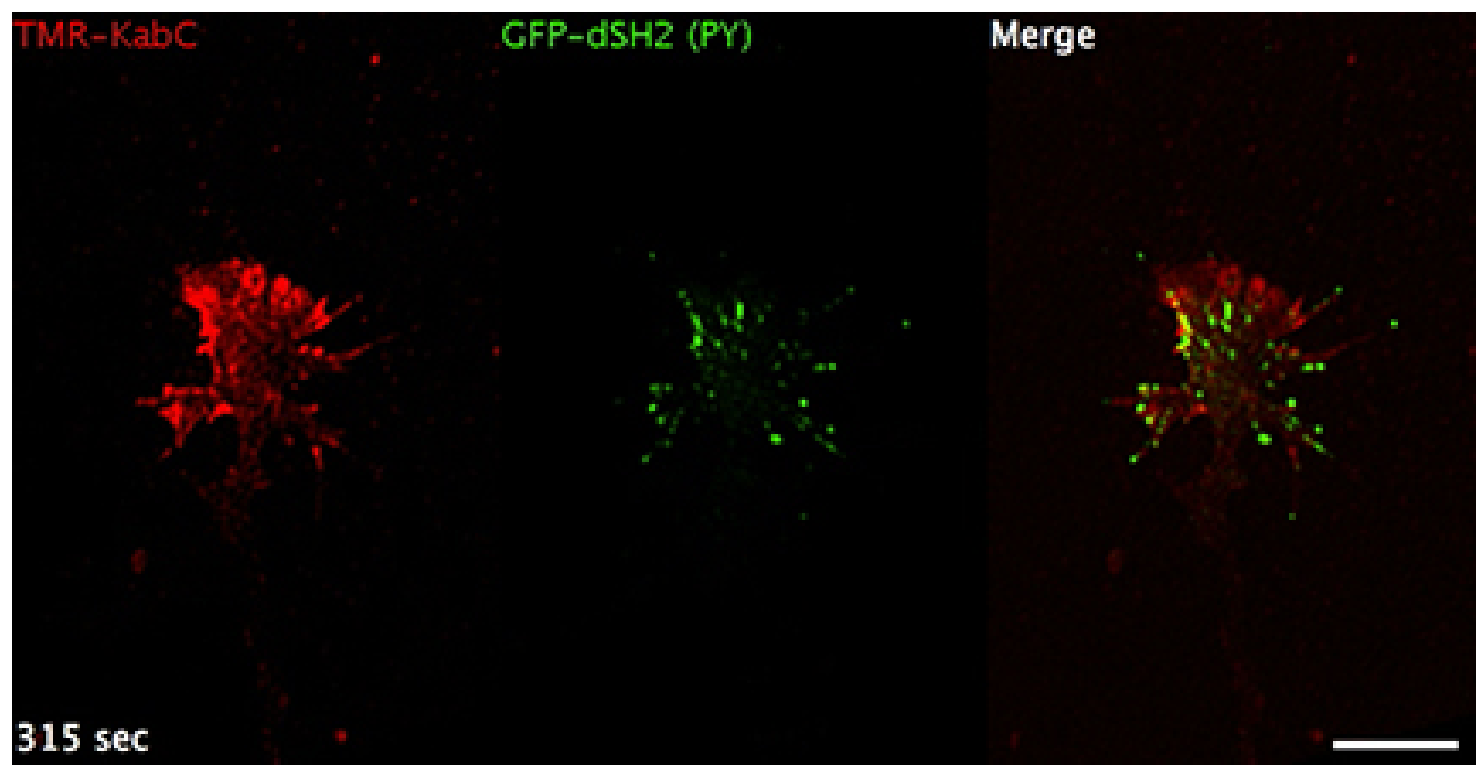

Movie 5. dSH2-GFP- and KabC-labeled growth cone on LN. Time-lapse confocal image sequence acquired with a $60 \times$ objective with 2.5 zoom of a growth cone on LN coexpressing dSH2-GFP and TMR-KabC. This image sequence includes the growth cone depicted in Figure $2 E$. Images were captured at $15 \mathrm{~s}$ intervals for $12.5 \mathrm{~min}$. Playback is 7 frames $/ \mathrm{s}$. Scale bar, $5 \mu \mathrm{m}$.
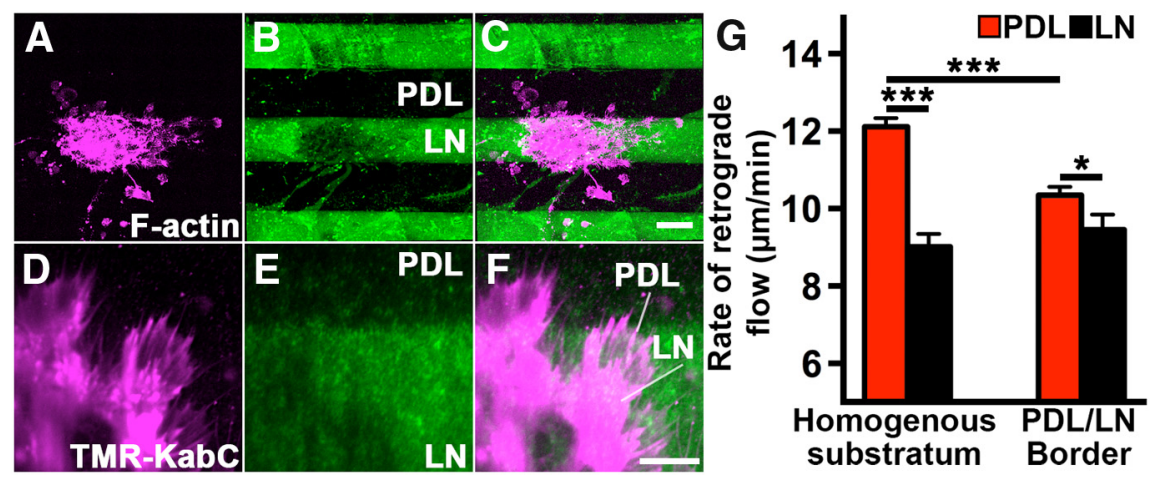

Figure 5. F-actin retrograde flow is locally regulated within growth cones at PDL/LN substrata borders. $\boldsymbol{A}-\boldsymbol{C}$, Lowmagnification images of Xenopus spinal cord explants labeled for F-actin using Alexa Fluor 546-phalloidin (A) cultured on a patterned substratum of alternating lanes of PDL and LN (B). Borders were visualized using fluorescent (HiLyte 488) LN (green). Pseudocolored image merge (C) shows strong preference for LN. Scale bar, $50 \mu \mathrm{m}$. $\boldsymbol{D}, \boldsymbol{E}$, High-magnification TIRF image of a growth cone labeled with TMR-KabC (D) spanning a PDL/LN border $(\boldsymbol{E})$. LN was-labeled with succinimidyl ester 647 (SE-647). $\boldsymbol{F}$, Merged image of TMR-KabC-labeled growth cone (magenta) spanning the border between LN (green) and PDL (unlabeled) with representative lines used to generate kymographs. $G$, Average rates of retrograde flow (RF) in growth cones spanning a PDL/LN border are significantly faster over PDL compared with LN ( $n=27$ growth cones). However, differences between LN ( $n=15$ growth cones) and PDL ( $n=10$ growth cones) are more dramatic on homogenous substrata (note that RF rates on homogenous substrata are data duplicated from Fig. 1 for comparison). Scale bar, $5 \mu \mathrm{m}$. ${ }^{* * *} p<0.001$; $^{*} p<0.05$.

erate "on" point contact kymographs (Fig. 4F). Areas within the leading edge devoid of point contacts were used to generate "off" point contact kymographs (Fig. 4G). F-actin bundles on point contacts showed a significant attenuation of RF velocity relative to $\mathrm{F}$-actin bundles not associated with point contacts (Fig. 4H). These data suggest that leading edge RF can be locally restrained at point contact adhesions in growth cones on LN and is not simply regulated as an ensemble contractile actin network.

Because RF can be modulated differentially within growth cones on homogenous LN, it is possible that changes in the adhesive substrata encountered by growth cones directs axon extension through local differences in clutching of RF. To test this as a possible mechanism of axon guidance, we cultured neurons on substratum patterns of PDL and LN (Fig. 5A-C), which we have shown previously promotes growth cone turn- ing (Gómez et al., 2001). Similar to chemotropic turning assays, patterned substrata have been used to elucidate mechanisms of chemical and mechanical guidance responses (Walter et al., 1987; Gómez and Letourneau, 1994; Evans et al., 2007; Knöll et al., 2007; Treloar et al., 2009; San Miguel-Ruiz and Letourneau, 2014). Xenopus spinal cord explants were cultured on striped patterns of PDL and LN created using a silicone mask as described previously (San Miguel-Ruiz and Letourneau, 2014). As expected, a clear preference for growth on $\mathrm{LN}$ was evident at low magnification (Fig. 5A-C). Growth cones spanning the PDL/LN border were loaded with TMRKabC and imaged by TIRF microscopy (Fig. 5D-F). Growth cones were selected if three kymograph lines could be generated within individual growth cones partially on each substrata. Therefore, F-actin RF velocities were compared from individual growth cones interacting with two distinct substrata (Fig. $5 F$ ). Using this experimental paradigm, we found that RF was significantly slower within local regions of growth cones on LN compared with PDL (Fig. 5G). It is interesting that, for growth cones spanning borders, the average rate of RF on PDL was significantly slower compared with homogenous PDL (10.35 \pm .22 vs $12.11 \pm 0.23, p<0.0001)$. These data suggest that F-actin clutching can be locally controlled at sites of ECM attachment, but that clutching of the entire F-actin network also contributes globally to rates of RF.

Soluble axon guidance cues modulate the rates of F-actin RF Growth-promoting and growth-inhibiting axon guidance cues can influence actin polymerization (Vitriol and Zheng, 2012) and point contact formation (Woo and Gómez, 2006; Myers et al., 2011), 
but it is not known how soluble cues regulate RF. We showed previously that, on $\mathrm{LN}$, brain-derived neurotrophic factor (BDNF) promotes point contact formation and enhances neurite outgrowth (Myers and Gómez, 2011), whereas Semaphorin3A (Sema3A) had the opposite effect (Woo and Gómez, 2006; Bechara et al., 2008). Therefore, we investigated how BDNF and Sema3A affect RF rates on PDL and LN in growth cones labeled with TMR-KabC. We found that treatment with $100 \mathrm{ng} / \mathrm{ml} \mathrm{BDNF}$ for 15 min did not significantly affect the RF rates in growth cones on PDL, but caused a marked decrease in RF on LN (Fig. $6 A-D, M$, Movie 6). This effect was observed specifically in the subpopulation of growth cones that exhibited protrusive responses to BDNF because unresponsive growth cones showed little change in RF in response to BDNF (data not shown). Because BDNF promotes point contact formation and strongly enhances axon extension on LN, but not PDL (Myers et al., 2011), these data suggest that point-contactinduced F-actin clutching is a key regulatory mechanism for attractive growth cone responses.

In contrast to BDNF, Sema3A is a repulsive axon guidance factor that disrupts existing growth cone point contacts and prevents new point contact formation (Woo and Gómez, 2006; Bechara et al., 2008). Therefore, if clutching of RF depends on point contacts, we expected that RF rates on LN, but not PDL, will be potentiated in response to Sema3A treatment. To test this, we imaged TMR-KabC-labeled growth cones plated on PDL or LN before and after treatment with a subcollapsing dose of Sema3A (400 ng/ml) for $15 \mathrm{~min}$. Growth cones that stalled in response to Sema3A were analyzed for changes in RF. At this dose, growth cone morphology was only modestly altered, indicating that Sema3A did not depolymerize F-actin. In contrast to the LN-specific effects of BDNF on RF, Sema3A increased RF in growth cones on both PDL (Fig. 6E-H) and LN (Fig. $6 I$, J, Movie 7). However, Sema3A treatment caused a greater increase in RF rates in growth cones on LN (Fig. 6M). The partial effect of Sema3A treatment on growth cones on PDL may be due to activation of both actin polymerization (Jurney et al., 2002) and RhoAdependent myosin contraction (Wu et al., 2005; Brown and Bridgman, 2009). In addition to activation of contraction, the stronger stimulation of RF for growth cones on LN may be due to acute disruption of point contacts, which would release the clutching forces normally restraining RF. Therefore, in coordination with ECM-mediated adhesion, attractive and repulsive axon guidance cues such as BDNF and Sema3A may regulate axon outgrowth and guidance by modulating rates of RF locally.

\section{Axonal growth cones exhibit slower actin retrograde flow} in vivo

Our in vitro assays suggest that clutching leading edge RF may control neurite outgrowth and guidance within developing embryos. To begin to investigate the role for RF as a potential regulator of axon guidance in vivo, we expressed Td-Tomato tractin, a peptide that specifically binds F-actin (Johnson and Schell, 2009; Saengsawang et al., 2012), in Rohon-Beard sensory neurons and commissural interneurons within the developing Xenopus neural tube by targeted blastomere injection (Fig. 7A). Specific classes of tractin-labeled neurons were identified via cell body position and axonal projection patterns in the exposed spinal cord preparations (SantiagoMedina et al., 2012) viewed at low magnification (Fig. 7B). Growth cones of Rohon-Beard sensory neurons extending along the dorsal fascicle of the neural tube, as well as growth cones of commissural interneurons extending ventrally toward the floor plate, were imaged at high speed and resolution to measure RF (Fig. 7C, Movie 8). Confocal optical sections were collected at a single focal plane $(\sim 700 \mathrm{~nm})$ from growth cones that remained in focus for the duration of the imaging sequence, allowing us to track linear movements of GFP-actin puncta accurately. Quantification of kymographs revealed that growth cones in vivo exhibit significantly slower RF compared with growth cones cultured on both PDL and LN (Fig. $7 D)$. Although the rate of RF in vivo could be slower due to 

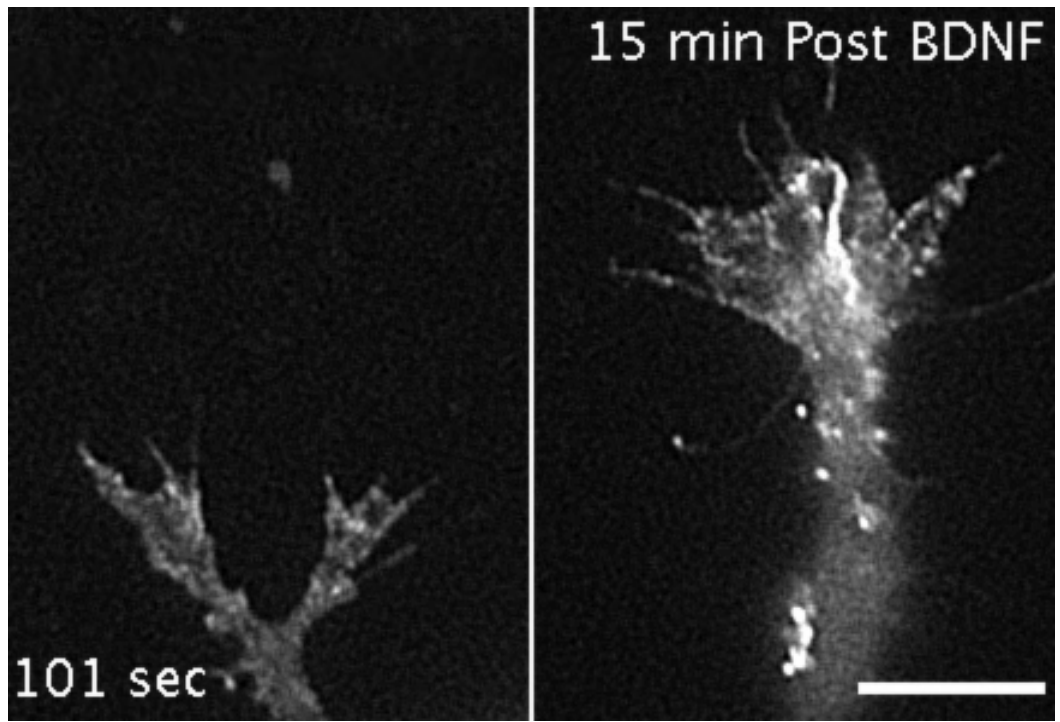

Movie 6. KabC-labeled growth cones on LN with acute BDNF stimulation. Time-lapse TIRF image sequence acquired with a $100 \times$ objective of a growth cone on LN labeled with TMR-KabC acutely stimulated with BDNF. Growth cones were imaged 5 min pre-BDNF and 15 min post-BDNF. This image sequence includes the growth cone depicted in Figure $6, A$ and $B$. Images were captured at $2 \mathrm{~s}$ intervals for $2 \mathrm{~min}$. Playback is 7 frames $/ \mathrm{s}$. Scale bar, $5 \mu \mathrm{m}$.
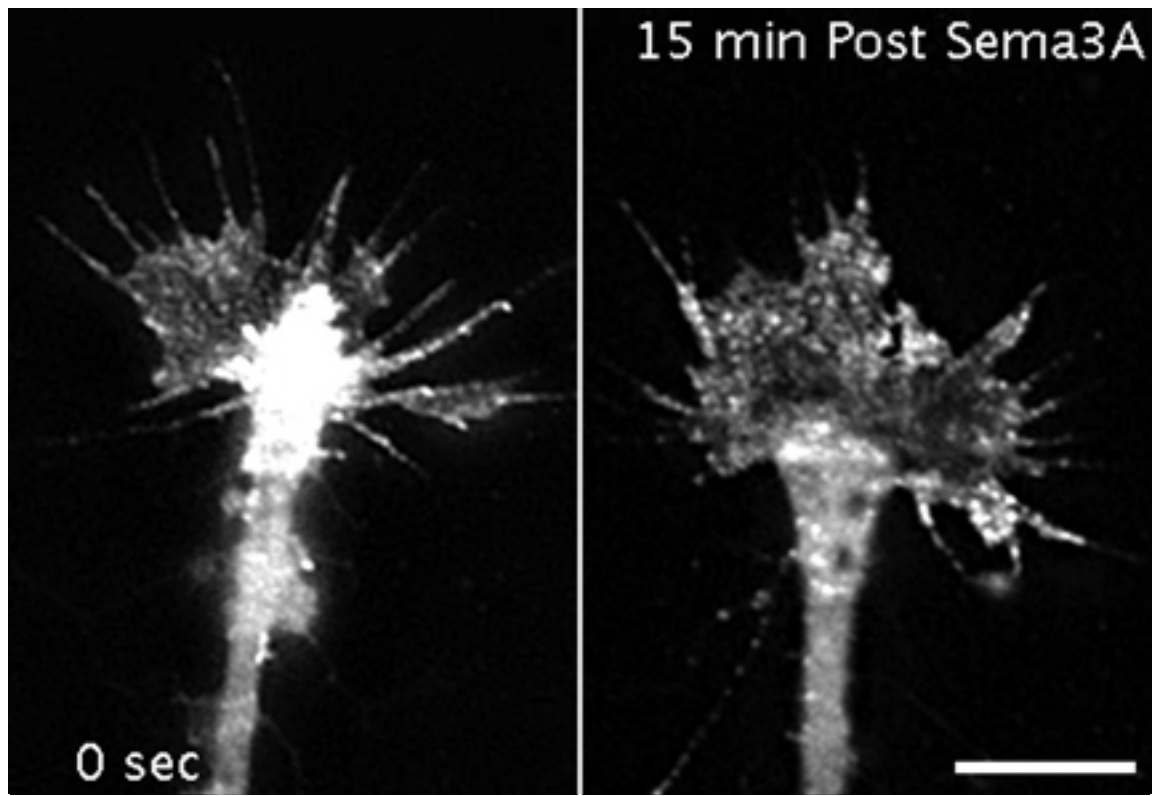

Movie 7. KabC-labeled growth cones on LN with acute Sema stimulation. Time-lapse TIRF image sequence acquired with a $100 \times$ objective of a growth cone on LN labeled with TMR-KabC acutely stimulated with Sema3A. Growth cones were imaged 5 min pre-Sema3A and $15 \mathrm{~min}$ post-Sema3A. Images were captured at 2 s intervals for $2 \mathrm{~min}$. Playback is 7 frames $/ \mathrm{s}$. Scale bar, $5 \mu \mathrm{m}$.

reduced myosin-II activity, it is possible that strong F-actin clutching within the $3 \mathrm{D}$ space of the developing embryo contributes to slow RF rates. Clutching of RF in vivo may occur through growth cone receptor interactions with ECM or cell adhesion molecule ligands present in the spinal cord (Myers et al., 2011). We confirmed that RF measurements made in vivo depend on myosin-II activity by treating embryos with blebbistatin (Fig. $7 F-H$ ), which reduced RF. However, the effects of blebbistatin on RF in vivo were less pronounced than we observed on LN in vitro (Fig. 1), which may be due to limited access to blebbistatin in vivo. Alternatively, adhesion complexes that clutch RF in vivo may also be disrupted by inhibi- tion of myosin-II, which would oppose the effects of inhibition of myosin-II on RF. Td-Tomato tractin was specifically used in these experiments because $488 \mathrm{~nm}$ excitation light photo-inactivates blebbistatin, precluding use of GFP-actin.

\section{Discussion}

Mechanical forces produced within growth cones are coordinated by extracellular factors to guide axon extension (Tyler, 2012; Kerstein et al., 2015). Protrusive forces are thought to be directed largely by regulated actin polymerization, but here we show that modulation of F-actin RF by clutching to point contact adhesion sites may be an equally important determinant for axon outgrowth and guidance (see Model). Using TMR-KabC and GFPactin to measure RF, we show that RF in growth cones depends on culture substratum and varies inversely with the rate of outgrowth (Model 1 $A, B$ ). We find that $\mathrm{RF}$ is slow and variable in highly motile growth cones on LN and in vivo. The variability of RF rates locally within individual growth cones on LN suggests that there is local modulation of clutching, which we demonstrate occurs at sites of paxillincontaining point contact adhesions. Differential rates of RF also correlate with locations of leading edge protrusion and retraction, suggesting that localized clutching may regulate axon guidance (Model 1C,D). Consistent with this notion, we show that local differences in RF rates occur within growth cones spanning substratum boundaries. Finally, we show that soluble axon guidance cues that modulate point contact adhesion assembly and disassembly also affect RF rates on $\mathrm{LN}$, suggesting that axons associated with ECM in vivo may be guided by local modulation of F-actin clutching.

Although clutching of RF has been hypothesized as a guiding force for developing axons (Mitchison and Kirschner, 1988; Suter et al., 1998; Bard et al., 2008; Shimada et al., 2008; Toriyama et al., 2013; Garcia et al., 2015), our study provides the first evidence of clutchdependent axon extension and guidance on an ECM substratum. The clutch hypothesis was initially described by Mitchison and Kirschner (1988) and has been largely examined for clutching to cell adhesion molecules (CAMs). In Aplysia growth cones, a local reduction in RF upon contact with immobilized Aplysia CAM (apCAM)-coated beads correlates with the targeted invasion of microtubules from the central domain toward the restrained bead, suggesting preferential growth in the direction of clutched RF (Suter et al., 1998). However, due to the slow growth rate of Aplysia axons, studying the effect of clutching on overall outgrowth or local guidance is limited. In this study, we show that 
clutching to point contact adhesions is necessary for LN, as well as BDNF- and Sema3A-induced changes in RF, which correlates with local protrusion and retraction. Similar to apCAM, L1 clutches and attenuates RF through the adapter protein shootin to promote axonal outgrowth downstream of Netrin-1 (Shimada et al., 2008; Toriyama et al., 2013). More recently, local coupling of F-actin to $\mathrm{N}$-cadherin through $\alpha$-catenin was found to clutch RF locally on $\mathrm{N}$-cadherin micropatterns (Bard et al., 2008; Garcia et al., 2015). Therefore, it appears that CAM protein complexes function to link F-actin and restrain RF to promote axon outgrowth through distinct adaptor proteins. However, whether integrin-ECM adhesion complexes use similar mechanisms has not been examined. Although cell-cell adhesive interactions play key roles in axon tract formation, pioneering growth cones often navigate through a complex ECM (Myers et al., 2011). Immobilized ECM proteins form a rigid substrata that enables traction forces necessary for force generation (Gardel et al., 2008; Moore et al., 2009; Koch et al., 2012; Moore et al., 2012). In addition, pioneering axons secrete matrix metalloproteases to remodel their local ECM, making substratum interactions highly dynamic (Santiago-Medina et al., 2015). Our study is the first to show that modulation of clutching of F-actin RF at point contact adhesions regulates local protrusion and retraction at the growth cone leading edge downstream of permissive and repulsive axon guidance cues.

Experiments testing the effects of soluble versus substratum-associated LN suggest that signaling pathways regulate growth cone motility downstream of integrin receptor activation and clustering. Integrin clustering is known to occur in response to immobilized but not soluble ligands (Cluzel et al., 2005). Integrin clustering leads to recruitment and phosphorylation of adhesion adaptor proteins such as paxillin and FAK (Robles and Gómez, 2006; Myers et al., 2011). The additional downstream signals activated by substratum-bound LN may be due to integrin receptor clustering that provides "mechanical" activation of growth cones. It is unclear how integrin receptor clustering on immobilized LN promotes additional signaling in growth cones. However, clustered integrins do activate RhoA and ROCK (Cluzel et al., 2005), which increases MLC2 phosphorylation at Ser19 (Woo and Gómez, 2006) to promote F-actin contractile
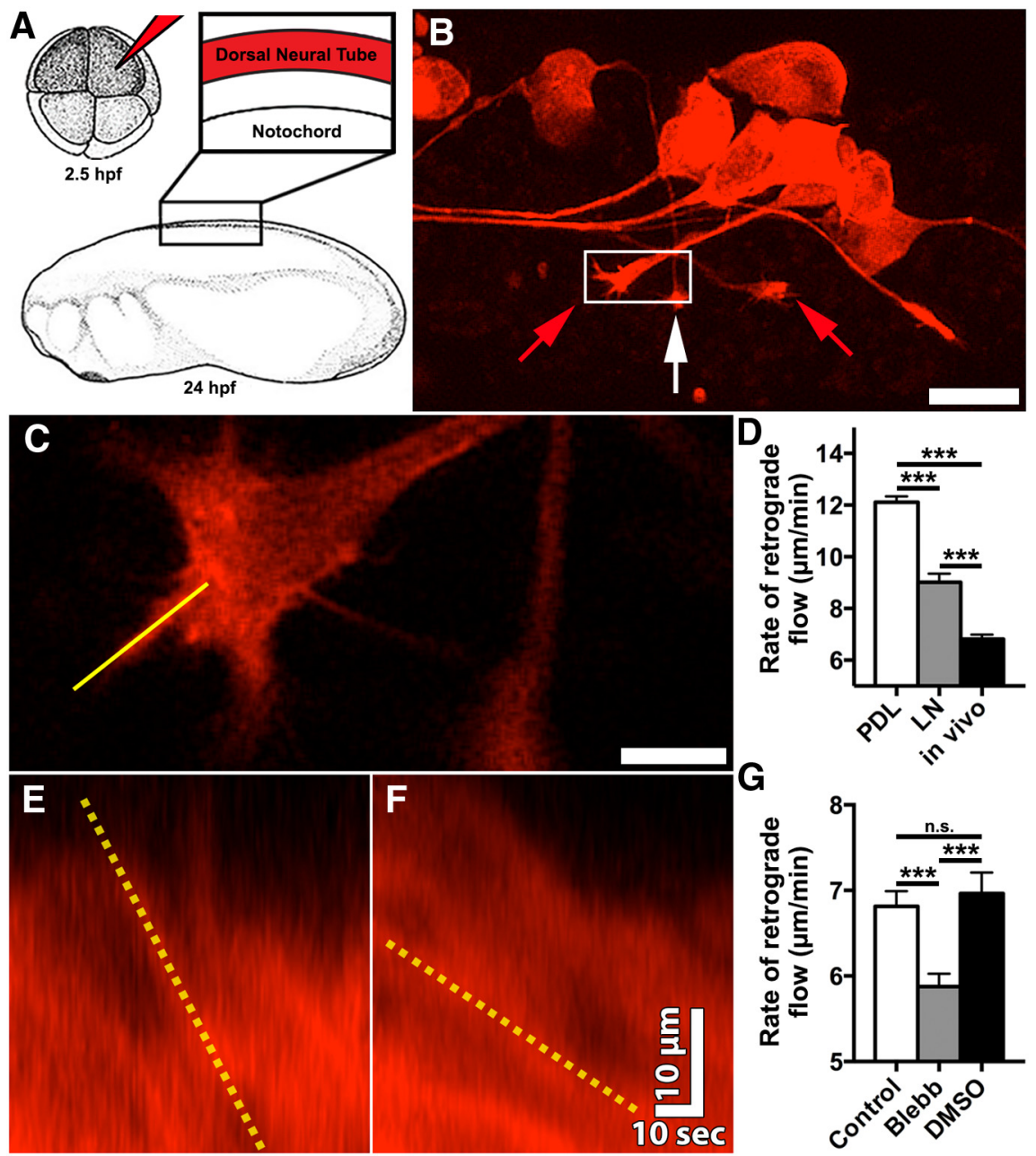

Figure 7. Axonal growth cones exhibit slow actin retrograde flow (RF) in vivo. A, Schematic illustrating blastomere injection of DNA plasmid encoding Td-Tomato tractin targeted to the dorsal spinal cord. Embryos were allowed to develop to $24 \mathrm{~h}$ postfertilization (hpf) before exposing spinal cord for live imaging. $\boldsymbol{B}$, Low-magnification and contrast stretched confocal $z$-series projection showing F-actin-labeled Rohon-Beard neuron (red arrow) and commissural interneuron (white arrow). An ascending RB axon is tipped by a growth cone (box). Scale bar, $30 \mu \mathrm{m}$. C, High-magnification image from time series used to generate kymographs (yellow line) of growth cone from boxed region in $\boldsymbol{B}$. Scale bar, $5 \mu \mathrm{m}$. $\boldsymbol{D}$, Rate of RF in vivo ( $n=19$ growth cones) is significantly slower than RF rates observed in cultured neurons on PDL and $10 \mu \mathrm{g} / \mathrm{ml}$ LN. $\boldsymbol{E}, \boldsymbol{F}$, Kymographs generated from 2 min time-lapse sequences of a tractin-labeled growth cone before $(\boldsymbol{E})$ and after $(\boldsymbol{F})$ inhibition of myosin II with $50 \mu \mathrm{m}$ blebbistatin. Dashed yellow lines indicated example flow lines used to calculate rates. $\boldsymbol{G}$, ztate of $\mathrm{RF}$ after blebbistatin treatment is significantly reduced relative to pretreatment and DMSO control media. Scale bar, $\left.10 \mu \mathrm{m} .{ }^{* * *} p<0.001\right)$.

\section{Td-Tom Tractin}

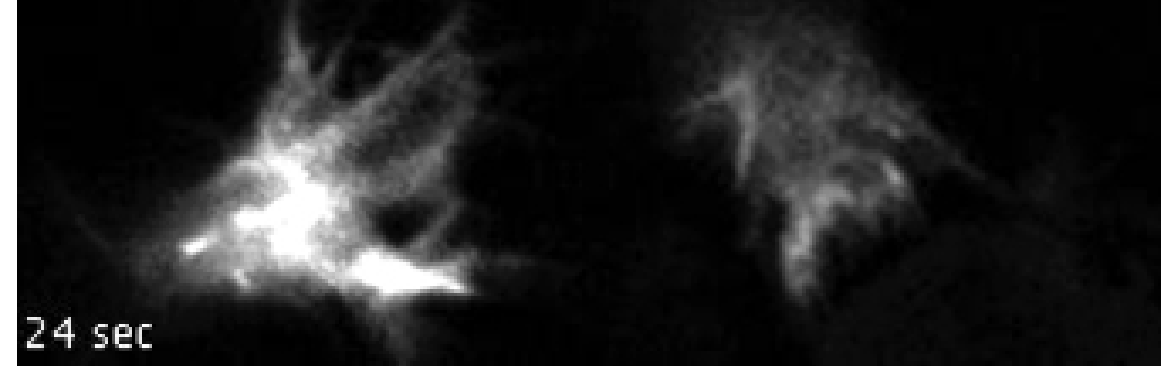

Movie 8. Td-Tomato Tractin-expressing growth cones in vivo. Time-lapse confocal image sequence acquired with a $60 \times$ objective with 2.5 zoom of Xenopus spinal growth cones in vivo expressing Td-Tomato Tractin. Images were captured at 1 sintervals for 74 s. Playback is 7 frames $/ \mathrm{s}$. 
A

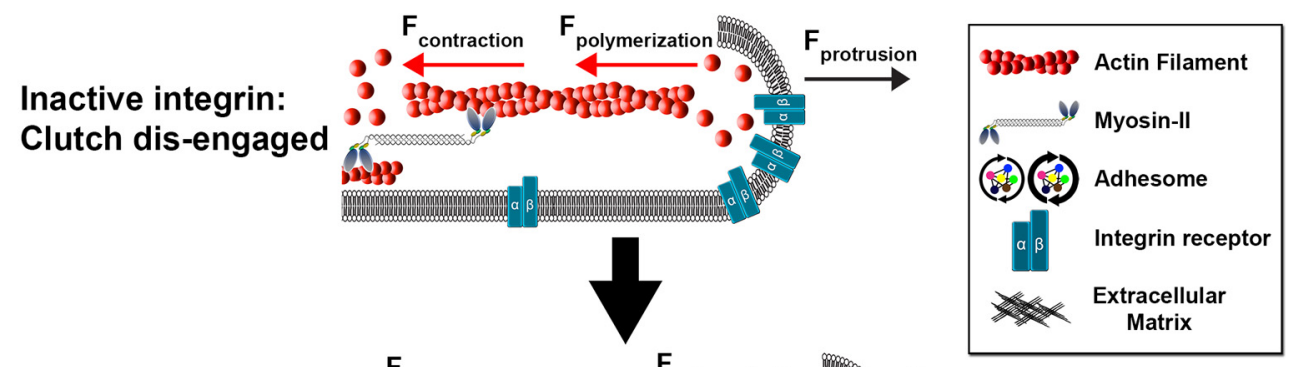

B
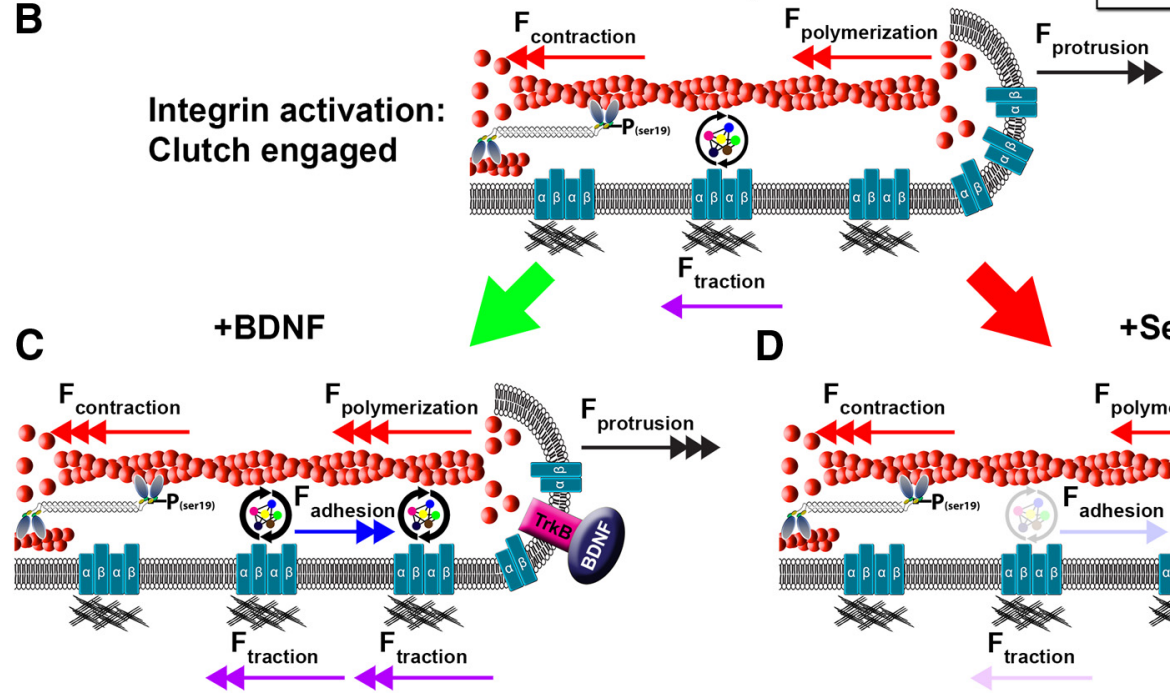

traction

D

+Sema3A

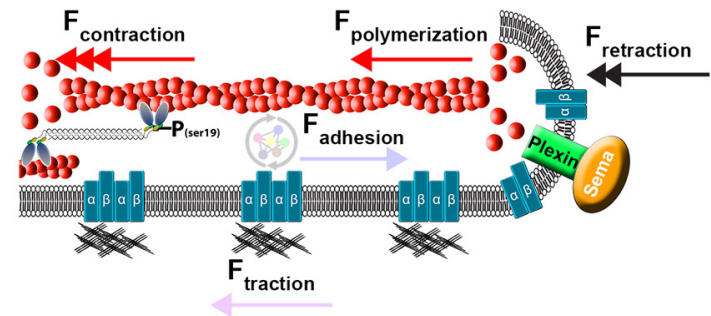

Model 1. Regulation of protrusion through modulation of integrin-dependent F-actin clutching by axon guidance cues. Actin filaments populating the leading edge of growth cones undergo constant retrograde flow (RF) due to proximal myosin-II mediated contractile forces $\left(F_{\text {contraction }}\right)$ and distal actin polymerization, which pushes against the plasma membrane to propel filaments rearward $\left(F_{\text {polymerization }}\right)$. $A$, In the absence of integrin activation and clustering, the molecular clutch is disengaged and $F_{\text {contraction }}$ and $F_{\text {polymerization }}$ drive rapid actin RF. However, even under low clutching conditions, leading edge actin polymerization can at times exceed RF, resulting in modest forward protrusion $\left(F_{\text {protrusion }}\right)$ and some forward translocation of the growth cone. $B$, In the presence of extracellular matrix (ECM) proteins, integrin receptors are activated and cluster and recruit adhesome-related adaptor and signaling proteins to form point contact adhesions, which link to actin filaments. Point contact adhesions form a slip clutch with actin filaments $\left(F_{\text {adhesion }}\right)$, which restricts RF and generates traction forces $\left(F_{\text {traction }}\right)$ on the ECM. Integrin activation also increases myosin-ll activity and actin polymerization, which should increase actin RF. However, faster RF is overcome by point-contact-mediated clutching, which promotes forward growth cone translocation. C, BDNF increases point contact formation and turnover (Myers and Gómez, 2011) and promotes actin polymerization, as well as myosin-ll activation (Gehler et al., 2004). However, more point contact adhesions that are rapidly turning over further clutch RF to increase forward protrusion and accelerate axon outgrowth. D, Sema3A, a repulsive axon guidance cue, promotesthedisassembly of point contacts (Woo and Gómez, 2006), which disrupts F-actin clutching to minimize $F_{\text {adhesion }}$ and $F_{\text {traction }}$. In addition, Sema3A activates RhoA and ROCK, resulting in phosphorylation of myosin-Il at Ser19, to increase $F_{\text {contraction }}$ (Gallo, 2006). Loss of point contact clutching and increased $F_{\text {contraction }}$ leads to strong activation of RF and subsequent axon stalling and retraction.

forces (Vicente-Manzanares et al., 2009). The RhoA-ROCKmyosin-II signaling cascade acts as a feedback control to further stabilize and mature adhesions in the lamellipodia of migrating cells (Chrzanowska-Wodnicka and Burridge, 1996; Vicente-Manzanares et al., 2009). Interestingly, previous work showed a similar requirement of immobilized Netrin and myosin contractile forces in the activation of FAK and p130-Cas (Moore et al., 2012). Inhibition of myosin-II prevented activation of FAK and p130-Cas downstream of stimulation with substratum-associated Netrin (Moore et al., 2012). P130-Cas forms a complex with the adaptor molecule Crk to induce downstream activation of Rho GTPases such as Racl and Cdc42 (Liu et al., 2007). These data suggest the importance of mechanosensitive signaling molecules in point contact adhesions. The early targeting of adaptor proteins to activated and clustered integrins may promote local myosin-II-mediated F-actin contractile forces. These mechanical forces may promote further phosphorylation and clustering of putative mechanosensitive molecules (Moore et al., 2010; Ciobanasu et al., 2014). Several molecules that target to growth cone point contacts have been shown to function as mechanosensors, including talin (del Rio et al., 2009), FAK (Wang et al., 2001), vinculin (Grashoff et al., 2010), and p130-Cas (Sawada et al., 2006). These proteins are unfolded by "stretching" of the protein, which is believed to expose cryptic protein binding and phosphory- lation sites, leading to further maturation of adhesions (VicenteManzanares et al., 2009; Moore et al., 2010).

In motile growth cones, actin treadmilling is believed to be driven by both pulling forces from myosin-II-motor-mediated F-actin sliding and pushing forces at the membrane from barbed-end actin polymerization at the leading edge (Forscher and Smith, 1988; Lin and Forscher, 1995; Brown and Bridgman, 2003). In contrast, the distal lamellipodium of migrating, non-neuronal cells lacks myosin II-mediated contractile forces and RF is largely powered by leading edge actin polymerization (Ponti et al., 2004; Vicente-Manzanares et al., 2009). In fibroblasts, myosin-II is localized proximal to the lamellipodium within the lamellum region, where it organizes actin and contributes to RF. However, actomyosin filaments in neuronal growth cones are not such rigidly organized structures and are much more dynamic. The unique morphology and dynamics of growth cones suggest that they possess distinct mechanisms governing traction forces at the leading edge. Indeed, myosin-II is highly expressed in the growth cone central domain, transition zone, and, to a lesser extent, along F-actin bundles in the peripheral domain (Bridgman et al., 2001; Medeiros et al., 2006; Burnette et al., 2008). Our findings verify the function of myosin-II in the growth cone peripheral domain because blebbistatin treatment reduces $\mathrm{RF}$ rates at the leading edge. Together with previous evidence (Bridgman et al., 2001), our 
findings suggest that chemotropic factors could target myosin-II to regulate $\mathrm{RF}$ and direct growth cone motility.

It is important to note that we found that the rates of RF were only partially reduced by inhibition of myosin-II (Fig. $1 \mathrm{H}, I$ ). Moreover, we found that the effects of myosin-II inhibition on $\mathrm{RF}$ rates were greater for growth cones on PDL compared with $\mathrm{LN}$ and compared with growth cones in vivo (Fig. 1I). This difference may be due to the disruption of point contact adhesions of growth cones on LN and in vivo by myosin-II inhibition (Woo and Gómez, 2006), which would balance the loss of myosin-II motor activity. Interestingly, these data suggest that the rate of actin polymerization is greater on LN compared with PDL because the rate of RF is higher on LN compared with PDL under conditions in which adhesions are lost and myosin-II is inactivated. Heightened actin polymerization on $\mathrm{LN}$ is consistent with integrin-activated signals such as Src/FAK tyrosine kinase signaling (Fig. 3) that can activate Cdc42 and Racl (Woo and Gómez, 2006; Myers et al., 2012).

Local differences in RF rates within growth cones at sites of point contact adhesions (Fig. 4E-I) suggest that local clutching can slow RF regionally within the actin filament network. Discontinuities of RF correlate with areas of leading edge protrusion and retraction (Fig. $4 A-D$ ), suggesting that localized clutching may influence the direction of outgrowth. Sites of local protrusion are associated with areas of increased actin polymerization (Mallavarapu and Mitchison, 1999; Krause and Gautreau, 2014), which is expected to increase RF (Van Goor et al., 2012). Therefore, our observations of reduced RF at sites of membrane protrusion suggest that clutching forces are highest in protrusive areas, which is consistent with traction force microscopy showing elevated traction forces at focal adhesions (Gardel et al., 2008) and in the direction of cell migration (Munevar et al., 2001).

We have demonstrated previously that soluble axon guidance cues modulate growth cone motility in part through modulation of integrin point contact adhesion dynamics (assembly and turnover; Woo and Gómez, 2006; Woo et al., 2009; Myers et al., 2011). Specifically, BDNF promotes axon outgrowth by stimulating adhesion assembly and turnover (Myers et al., 2011), whereas Sema3A destabilizes adhesions (Woo and Gómez, 2006). Consistent with links between point contact adhesions and RF, we show here that BDNF slows RF specifically in growth cones on LN (Fig. 6, Model $1 C$ ), whereas Sema3A increases RF most robustly in growth cones on LN (Fig. 6, Model 1D). These results further imply that soluble cues may affect axon guidance differentially depending on the cell substratum. Growth cones use a variety of insoluble protein substrata to support traction forces during axon extension in vivo, including a variety of ECM proteins and cell adhesion molecules. Actin RF is also restricted through associations with cell adhesion molecules such as IgCAM and L1 (Suter et al., 1998; Shimada et al., 2008), which can be regulated by axon guidance cues. We show here that RF occurs in vivo, but is slower relative to RF observed on homogenous $\mathrm{LN}$ in vitro. The identity of extracellular substrata and intracellular adaptor proteins is unclear in vivo, but RF rates are closer to those observed on cell adhesion molecules. It is known that combinatorial activities of permissive, attractive, and repulsive guidance cues encountered simultaneously in vivo are integrated by growth cones to regulate axon pathfinding behaviors necessary to build complex neural networks (Dudanova and Klein, 2013). Future studies should attempt to interfere specifically with clutching forces in vivo to determine whether modulation of RF plays a significant role in axon pathfinding in vivo.

\section{References}

Antar LN, Li C, Zhang H, Carroll RC, Bassell GJ (2006) Local functions for FMRP in axon growth cone motility and activity-dependent regulation of filopodia and spine synapses. Mol Cell Neurosci 32:37-48. CrossRef Medline

Bamburg JR (1999) Proteins of the ADF/cofilin family: essential regulators of actin dynamics. Annu Rev Cell Dev Biol 15:185-230. CrossRef Medline

Bard L, Boscher C, Lambert M, Mège RM, Choquet D, Thoumine O (2008) A molecular clutch between the actin flow and N-cadherin adhesions drives growth cone migration. J Neurosci 28:5879-5890. CrossRef Medline

Bechara A, Nawabi H, Moret F, Yaron A, Weaver E, Bozon M, Abouzid K, Guan JL, Tessier-Lavigne M, Lemmon V, Castellani V (2008) FAKMAPK-dependent adhesion disassembly downstream of L1 contributes to semaphorin3A-induced collapse. EMBO J 27:1549-1562. CrossRef Medline

Beck K, Hunter I, Engel J (1990) Structure and function of laminin: anatomy of a multidomain glycoprotein. FASEB J 4:148-160. Medline

Bridgman PC, Dave S, Asnes CF, Tullio AN, Adelstein RS (2001) Myosin IIB is required for growth cone motility. J Neurosci 21:6159-6169. Medline

Brown JA, Bridgman PC (2009) Disruption of the cytoskeleton during Semaphorin $3 \mathrm{~A}$ induced growth cone collapse correlates with differences in actin organization and associated binding proteins. Dev Neurobiol 69:633-646. CrossRef Medline

Brown ME, Bridgman PC (2003) Retrograde flow rate is increased in growth cones from myosin IIB knockout mice. J Cell Sci 116:1087-1094. CrossRef Medline

Burnette DT, Ji L, Schaefer AW, Medeiros NA, Danuser G, Forscher P (2008) Myosin II activity facilitates microtubule bundling in the neuronal growth cone neck. Dev Cell 15:163-169. CrossRef Medline

Carlier MF, Pantaloni D (2007) Control of actin assembly dynamics in cell motility. J Biol Chem 282:23005-23009. CrossRef Medline

Choi CK, Vicente-Manzanares M, Zareno J, Whitmore LA, Mogilner A, Horwitz AR (2008) Actin and alpha-actinin orchestrate the assembly and maturation of nascent adhesions in a myosin II motor-independent manner. Nat Cell Biol 10:1039-1050. CrossRef Medline

Chrzanowska-Wodnicka M, Burridge K (1996) Rho-stimulated contractility drives the formation of stress fibers and focal adhesions. J Cell Biol 133:1403-1415. CrossRef Medline

Ciobanasu C, Faivre B, Le Clainche C (2014) Actomyosin-dependent formation of the mechanosensitive talin-vinculin complex reinforces actin anchoring. Nat Commun 5:3095. Medline

Cluzel C, Saltel F, Lussi J, Paulhe F, Imhof BA, Wehrle-Haller B (2005) The mechanisms and dynamics of (alpha) $\mathrm{v}$ (beta) 3 integrin clustering in living cells. J Cell Biol 171:383-392. CrossRef Medline

Craig EM, Van Goor D, Forscher P, Mogilner A (2012) Membrane tension, myosin force, and actin turnover maintain actin treadmill in the nerve growth cone. Biophys J 102:1503-1513. CrossRef Medline

del Rio A, Perez-Jimenez R, Liu R, Roca-Cusachs P, Fernandez JM, Sheetz MP (2009) Stretching single talin rod molecules activates vinculin binding. Science 323:638-641. CrossRef Medline

Dent EW, Gupton SL, Gertler FB (2011) The growth cone cytoskeleton in axon outgrowth and guidance. Cold Spring Harb Perspect Biol 3: pii: a001800. CrossRef Medline

Dudanova I, Klein R (2013) Integration of guidance cues: parallel signaling and crosstalk. Trends Neurosci 36:295-304. CrossRef Medline

Evans AR, Euteneuer S, Chavez E, Mullen LM, Hui EE, Bhatia SN, Ryan AF (2007) Laminin and fibronectin modulate inner ear spiral ganglion neurite outgrowth in an in vitro alternate choice assay. Dev Neurobiol 67: 1721-1730. CrossRef Medline

Flynn KC, Hellal F, Neukirchen D, Jacob S, Tahirovic S, Dupraz S, Stern S, Garvalov BK, Gurniak C, Shaw AE, Meyn L, Wedlich-Söldner R, Bamburg JR, Small JV, Witke W, Bradke F (2012) ADF/cofilin-mediated actin retrograde flow directs neurite formation in the developing brain. Neuron 76:1091-1107. CrossRef Medline

Forscher P, Smith SJ (1988) Actions of cytochalasins on the organization of actin filaments and microtubules in a neuronal growth cone. J Cell Biol 107:1505-1516. CrossRef Medline

Gallo G (2006) RhoA-kinase coordinates F-actin organization and myosin II activity during semaphorin-3A-induced axon retraction. J Cell Sci 119: 3413-3423. CrossRef Medline

Garcia M, Leduc C, Lagardère M, Argento A, Sibarita JB, Thoumine O (2015) 
Two-tiered coupling between flowing actin and immobilized N-cadherin/catenin complexes in neuronal growth cones. Proc Natl Acad Sci U S A 112:6997-7002. CrossRef Medline

Gardel ML, Sabass B, Ji L, Danuser G, Schwarz US, Waterman CM (2008) Traction stress in focal adhesions correlates biphasically with actin retrograde flow speed. J Cell Biol 183:999-1005. CrossRef Medline

Gehler S, Gallo G, Veien E, Letourneau PC (2004) p75 neurotrophin receptor signaling regulates growth cone filopodial dynamics through modulating RhoA activity. J Neurosci 24:4363-4372. CrossRef Medline

Giannone G, Mège RM, Thoumine O (2009) Multi-level molecular clutches in motile cell processes. Trends Cell Biol 19:475-486. CrossRef Medline

Gómez TM, Letourneau PC (1994) Filopodia initiate choices made by sensory neuron growth cones at laminin/fibronectin borders in vitro. J Neurosci 14:5959-5972. Medline

Gómez TM, Robles E, Poo M, Spitzer NC (2001) Filopodial calcium transients promote substrate-dependent growth cone turning. Science 291: 1983-1987. CrossRef Medline

Gómez TM, Harrigan D, Henley J, Robles E (2003) Working with Xenopus spinal neurons in live cell culture. Methods Cell Biol 71:129-156. CrossRef Medline

Grashoff C, Hoffman BD, Brenner MD, Zhou R, Parsons M, Yang MT, McLean MA, Sligar SG, Chen CS, Ha T, Schwartz MA (2010) Measuring mechanical tension across vinculin reveals regulation of focal adhesion dynamics. Nature 466:263-266. CrossRef Medline

Johnson HW, Schell MJ (2009) Neuronal IP3 3-kinase is an F-actinbundling protein: role in dendritic targeting and regulation of spine morphology. Mol Biol Cell 20:5166-5180. CrossRef Medline

Jurney WM, Gallo G, Letourneau PC, McLoon SC (2002) Rac1-mediated endocytosis during ephrin-A2- and semaphorin 3A-induced growth cone collapse. J Neurosci 22:6019-6028. Medline

Keren K, Pincus Z, Allen GM, Barnhart EL, Marriott G, Mogilner A, Theriot JA (2008) Mechanism of shape determination in motile cells. Nature 453:475-480. CrossRef Medline

Kerstein PC, Nichol RH 4th, Gómez TM (2015) Mechanochemical regulation of growth cone motility. Front Cell Neurosci 9:244. Medline

Knöll B, Weinl C, Nordheim A, Bonhoeffer F (2007) Stripe assay to examine axonal guidance and cell migration. Nat Protoc 2:1216-1224. CrossRef Medline

Koch D, Rosoff WJ, Jiang J, Geller HM, Urbach JS (2012) Strength in the periphery: growth cone biomechanics and substrate rigidity response in peripheral and central nervous system neurons. Biophys J 102:452-460. CrossRef Medline

Krause M, Gautreau A (2014) Steering cell migration: lamellipodium dynamics and the regulation of directional persistence. Nat Rev Mol Cell Biol 15:577-590. CrossRef Medline

Kubo Y, Baba K, Toriyama M, Minegishi T, Sugiura T, Kozawa S, Ikeda K, Inagaki N (2015) Shootin1-cortactin interaction mediates signal-force transduction for axon outgrowth. J Cell Biol 210:663-676. CrossRef Medline

Lin CH, Forscher P (1995) Growth cone advance is inversely proportional to retrograde F-actin flow. Neuron 14:763-771. CrossRef Medline

Lin CH, Espreafico EM, Mooseker MS, Forscher P (1996) Myosin drives retrograde F-actin flow in neuronal growth cones. Neuron 16:769-782. CrossRef Medline

Liu G, Li W, Gao X, Li X, Jürgensen C, Park HT, Shin NY, Yu J, He ML, Hanks SK, Wu JY, Guan KL, Rao Y (2007) p130CAS is required for netrin signaling and commissural axon guidance. J Neurosci 27:957-968. CrossRef Medline

Lowery LA, Van Vactor D (2009) The trip of the tip: understanding the growth cone machinery. Nat Rev Mol Cell Biol 10:332-343. CrossRef Medline

Mallavarapu A, Mitchison T (1999) Regulated actin cytoskeleton assembly at filopodium tips controls their extension and retraction. J Cell Biol 146:1097-1106. CrossRef Medline

Marsick BM, Flynn KC, Santiago-Medina M, Bamburg JR, Letourneau PC (2010) Activation of ADF/cofilin mediates attractive growth cone turning toward nerve growth factor and netrin-1. Dev Neurobiol 70:565-588. CrossRef Medline

Medeiros NA, Burnette DT, Forscher P (2006) Myosin II functions in actinbundle turnover in neuronal growth cones. Nat Cell Biol 8:215-226. Medline
Mitchison T, Kirschner M (1988) Cytoskeletal dynamics and nerve growth. Neuron 1:761-772. CrossRef Medline

Mogilner A, Oster G (2003) Polymer motors: pushing out the front and pulling up the back. Curr Biol 13:R721-R733. CrossRef Medline

Moore SW, Biais N, Sheetz MP (2009) Traction on immobilized netrin-1 is sufficient to reorient axons. Science 325:166. CrossRef Medline

Moore SW, Roca-Cusachs P, Sheetz MP (2010) Stretchy proteins on stretchy substrates: the important elements of integrin-mediated rigidity sensing. Dev Cell 19:194-206. CrossRef Medline

Moore SW, Zhang X, Lynch CD, Sheetz MP (2012) Netrin-1 attracts axons through FAK-dependent mechanotransduction. J Neurosci 32:1157411585. CrossRef Medline

Munevar S, Wang YL, Dembo M (2001) Distinct roles of frontal and rear cell-substrate adhesions in fibroblast migration. Mol Biol Cell 12: 3947-3954. CrossRef Medline

Myers JP, Gómez TM (2011) Focal adhesion kinase promotes integrin adhesion dynamics necessary for chemotropic turning of nerve growth cones. J Neurosci 31:13585-13595. CrossRef Medline

Myers JP, Santiago-Medina M, Gómez TM (2011) Regulation of axonal outgrowth and pathfinding by integrin-ECM interactions. Dev Neurobiol 71:901-923. CrossRef Medline

Myers JP, Robles E, Ducharme-Smith A, Gómez TM (2012) Focal adhesion kinase modulates Cdc42 activity downstream of positive and negative axon guidance cues. J Cell Sci 125:2918-2929. CrossRef Medline

Nie D, Di Nardo A, Han JM, Baharanyi H, Kramvis I, Huynh T, Dabora S, Codeluppi S, Pandolfi PP, Pasquale EB, Sahin M (2010) Tsc2-Rheb signaling regulates EphA-mediated axon guidance. Nat Neurosci 13: 163-172. CrossRef Medline

Nieuwkoop PD, Faber J (1994) Normal table of Xenopus laevis (Daudin). New York: Garland Publishing.

Petchprayoon C, Suwanborirux K, Tanaka J, Yan Y, Sakata T, Marriott G (2005) Fluorescent kabiramides: new probes to quantify actin in vitro and in vivo. Bioconjug Chem 16:1382-1389. CrossRef Medline

Ponti A, Machacek M, Gupton SL, Waterman-Storer CM, Danuser G (2004) Two distinct actin networks drive the protrusion of migrating cells. Science 305:1782-1786. CrossRef Medline

Riedl J, Crevenna AH, Kessenbrock K, Yu JH, Neukirchen D, Bista M, Bradke F, Jenne D, Holak TA, Werb Z, Sixt M, Wedlich-Soldner R (2008) Lifeact: a versatile marker to visualize F-actin. Nat Methods 5:605-607. CrossRef Medline

Robles E, Gómez TM (2006) Focal adhesion kinase signaling at sites of integrin-mediated adhesion controls axon pathfinding. Nat Neurosci 9:1274-1283. CrossRef Medline

Robles E, Woo S, Gómez TM (2005) Src-dependent tyrosine phosphorylation at the tips of growth cone filopodia promotes extension. J Neurosci 25:7669-7681. CrossRef Medline

Saengsawang W, Mitok K, Viesselmann C, Pietila L, Lumbard DC, Corey SJ, Dent EW (2012) The F-BAR protein CIP4 inhibits neurite formation by producing lamellipodial protrusions. Curr Biol 22:494-501. CrossRef Medline

San Miguel-Ruiz JE, Letourneau PC (2014) The role of Arp2/3 in growth cone actin dynamics and guidance is substrate dependent. J Neurosci 34:5895-5908. CrossRef Medline

Santiago-Medina M, Gregus KA, Gómez TM (2013) PAK-PIX interactions regulate adhesion dynamics and membrane protrusion to control neurite outgrowth. J Cell Sci 126:1122-1133. CrossRef Medline

Santiago-Medina M, Myers JP, Gómez TM (2012) Imaging adhesion and signaling dynamics in Xenopus laevis growth cones. Dev Neurobiol 72: 585-599. Medline

Santiago-Medina M, Gregus KA, Nichol RH, O’Toole SM, Gómez TM (2015) Regulation of ECM degradation and axon guidance by growth cone invadosomes. Development 142:486-496. CrossRef Medline

Sawada Y, Tamada M, Dubin-Thaler BJ, Cherniavskaya O, Sakai R, Tanaka S, Sheetz MP (2006) Force sensing by mechanical extension of the Src family kinase substrate p130Cas. Cell 127:1015-1026. CrossRef Medline

Shimada T, Toriyama M, Uemura K, Kamiguchi H, Sugiura T, Watanabe N, Inagaki N (2008) Shootin1 interacts with actin retrograde flow and L1CAM to promote axon outgrowth. J Cell Biol 181:817-829. CrossRef Medline

Smilenov LB, Mikhailov A, Pelham RJ, Marcantonio EE, Gundersen GG (1999) Focal adhesion motility revealed in stationary fibroblasts. Science 286:1172-1174. CrossRef Medline 
Suter DM, Errante LD, Belotserkovsky V, Forscher P (1998) The Ig superfamily cell adhesion molecule, apCAM, mediates growth cone steering by substratecytoskeletal coupling. J Cell Biol 141:227-240. CrossRef Medline

Symons MH, Mitchison TJ (1991) Control of actin polymerization in live and permeabilized fibroblasts. J Cell Biol 114:503-513. CrossRef Medline

Tehrani S, Tomasevic N, Weed S, Sakowicz R, Cooper JA (2007) Src phosphorylation of cortactin enhances actin assembly. Proc Natl Acad Sci U S A 104:11933-11938. CrossRef Medline

Thievessen I, Thompson PM, Berlemont S, Plevock KM, Plotnikov SV, Zemljic-Harpf A, Ross RS, Davidson MW, Danuser G, Campbell SL, Waterman CM (2013) Vinculin-actin interaction couples actin retrograde flow to focal adhesions, but is dispensable for focal adhesion growth. J Cell Biol 202:163-177. CrossRef Medline

Toriyama M, Kozawa S, Sakumura Y, Inagaki N (2013) Conversion of a signal into forces for axon outgrowth through Pak1-mediated shootin1 phosphorylation. Curr Biol 23:529-534. CrossRef Medline

Treloar HB, Ray A, Dinglasan LA, Schachner M, Greer CA (2009) Tenascin-C is an inhibitory boundary molecule in the developing olfactory bulb. J Neurosci 29:9405-9416. CrossRef Medline

Turney SG, Bridgman PC (2005) Laminin stimulates and guides axonal outgrowth via growth cone myosin II activity. Nat Neurosci 8:717-719. CrossRef Medline

Tyler WJ (2012) The mechanobiology of brain function. Nat Rev Neurosci 13:867-878. Medline

Van Goor D, Hyland C, Schaefer AW, Forscher P (2012) The role of actin turnover in retrograde actin network flow in neuronal growth cones. PLoS One 7:e30959. CrossRef Medline

Vicente-Manzanares M, Ma X, Adelstein RS, Horwitz AR (2009) Non- muscle myosin II takes centre stage in cell adhesion and migration. Nat Rev Mol Cell Biol 10:778-790. CrossRef Medline

Vitriol EA, Zheng JQ (2012) Growth cone travel in space and time: the cellular ensemble of cytoskeleton, adhesion, and membrane. Neuron 73 : 1068-1081. CrossRef Medline

Walter J, Henke-Fahle S, Bonhoeffer F (1987) Avoidance of posterior tectal membranes by temporal retinal axons. Development 101:909-913. Medline

Wang HB, Dembo M, Hanks SK, Wang Y (2001) Focal adhesion kinase is involved in mechanosensing during fibroblast migration. Proc Natl Acad Sci U S A 98:11295-11300. CrossRef Medline

Weitzdoerfer R, Dierssen M, Fountoulakis M, Lubec G (2001) Fetal life in Down syndrome starts with normal neuronal density but impaired dendritic spines and synaptosomal structure. J Neural Transm Suppl 61:59-70. Medline

Woo S, Gómez TM (2006) Rac1 and RhoA promote neurite outgrowth through formation and stabilization of growth cone point contacts. J Neurosci 26:1418-1428. CrossRef Medline

Woo S, Rowan DJ, Gómez TM (2009) Retinotopic mapping requires focal adhesion kinase-mediated regulation of growth cone adhesion. J Neurosci 29:13981-13991. CrossRef Medline

Wu KY, Hengst U, Cox LJ, Macosko EZ, Jeromin A, Urquhart ER, Jaffrey SR (2005) Local translation of RhoA regulates growth cone collapse. Nature 436:1020-1024. CrossRef Medline

Yamashiro S, Watanabe N (2014) A new link between the retrograde actin flow and focal adhesions. J Biochem 156:239-248. CrossRef Medline

Zhang XF, Hyland C, Van Goor D, Forscher P (2012) Calcineurindependent cofilin activation and increased retrograde actin flow drive 5-HT-dependent neurite outgrowth in Aplysia bag cell neurons. Mol Biol Cell 23:4833-4848. CrossRef Medline 